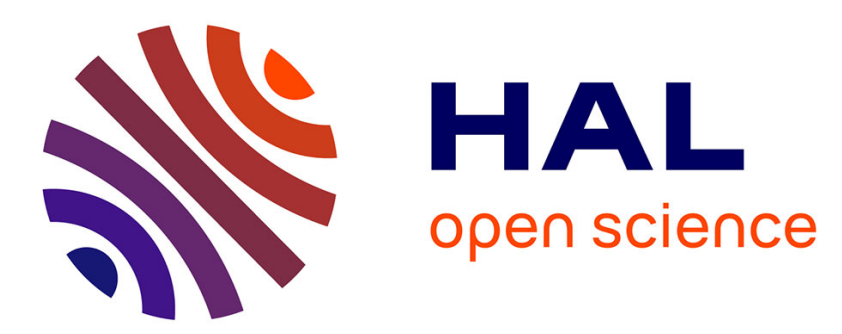

\title{
Analysis of the uncertainty in the estimates of regional PV power generation evaluated with the upscaling method
}

Yves-Marie Saint-Drenan, Garrett H. Good, Martin Braun, Thomas Freisinger

\section{- To cite this version:}

Yves-Marie Saint-Drenan, Garrett H. Good, Martin Braun, Thomas Freisinger. Analysis of the uncertainty in the estimates of regional PV power generation evaluated with the upscaling method. Solar Energy, 2016, 135, pp.536-550. 10.1016/j.solener.2016.05.052 . hal-02286930

\section{HAL Id: hal-02286930 \\ https://hal.science/hal-02286930}

Submitted on 26 Sep 2019

HAL is a multi-disciplinary open access archive for the deposit and dissemination of scientific research documents, whether they are published or not. The documents may come from teaching and research institutions in France or abroad, or from public or private research centers.
L'archive ouverte pluridisciplinaire HAL, est destinée au dépôt et à la diffusion de documents scientifiques de niveau recherche, publiés ou non, émanant des établissements d'enseignement et de recherche français ou étrangers, des laboratoires publics ou privés. 


\title{
Analysis of the uncertainty in the estimates of regional PV power generation evaluated with the upscaling method
}

\author{
Y.M. Saint-Drenan ${ }^{1, *}$, G. H. Good ${ }^{1}$, M. Braun ${ }^{1,2}$, T. Freisinger ${ }^{3}$ \\ ${ }^{1}$ Fraunhofer Institute for Wind Energy and Energy System Technology, Koenigstor 59, 34119 Kassel, Germany \\ ${ }^{2}$ University of Kassel, Wilhelmshöher Allee 71 - 73, 34121 Kassel, Germany \\ ${ }^{3}$ LEW Verteilnetz GmbH, Schaezlerstrasse 3, 86150 Augsburg, Germany
}

* Corresponding author. Tel.: +49 5617294 246; fax: +49 5617294260 E-mail address: yves-marie.saint-drenan@iwes.fraunhofer.de (Y.M. Saint-Drenan)

\begin{abstract}
The estimation of the regional photovoltaic (PV) power generation is an important step prior to the forecast of the PV power generation and its integration into the energy supply system. The large majority of PV plants not being measured in Germany, the total PV power generated in a region is commonly estimated by upscaling the power production of a set of reference PV plants to the entireness of the plants installed in the considered area. A given uncertainty can be expected in the estimation of the power generation of a PV plant with the upscaling method when the reference plants used have different configurations or weather conditions. To gain better insight into the performance of the upscaling method, its error has been analysed using power measurements of a set of $366 \mathrm{PV}$ plants. The analysis allows an understanding of the mechanisms underlying the uncertainty of the upscaling method and quantifies its error for the test study considered. In the case study analysed, it could be shown that the quarter hourly RMSE1 value decreases with an increasing number of reference plants and a decreasing number of un-metered plants. It could also be shown that even for a large number of reference plants, a variation of the RMSE between 0.01 and $0.025 \mathrm{~kW} / \mathrm{kWp}$ can be observed, depending on the choice of the reference plants. It is shown that the average distance between a reference and unknown plant constitutes a good indicator of the performance of a set of reference plants, but that the match between the characteristics of the reference and unknown plant also plays an important role, which could not be quantified with the available dataset.
\end{abstract}

\section{Introduction}

The upscaling algorithm is in Germany currently the standard approach for evaluating the PV power produced in a region. Most stakeholders in the energy sector implement this method for estimating the actual PV power generation using measurements from a set of reference plants and forecasting the future PV power generation using single-plant forecasts from a set of reference plants. This situation results amongst other factors from the recommendation made by the federal network agency (Bundesnetzagentur) in 2011 to encourage German energy suppliers to implement this method. Indeed, at that time it was common to use constant PV generation profiles for scheduling and balancing the energy supply, which lead to a critical situation in the Autumn of 2010 [Saint-Drenan

\footnotetext{
${ }^{1}$ In this paper, RMSE values are calculated with 15 min time averaged power values, which corresponds to the time resolution used for energy trading.
} 
et al 2011] [Thomaschki 2011] [Hoffmann 2011]. The implementation of the upscaling method by most transmission system operators, distribution system operators, energy suppliers and PV forecast suppliers thus represents a real progress in comparison to the previous state of the industry. Nevertheless, it is unclear how accurate this method is when only a limited number of reference plants are available. Indeed, in such situations two issues can penalize the accuracy of the upscaling method:

- The partial measurements of the irradiation field by a limited number of point measurements, and,

- Eventual differences between the characteristics of the reference and uncharacterized PV plants.

Application of the upscaling method for the estimation of the regional PV power generation has been the subject of different studies over the last years, in which some information on the uncertainty of this method have been highlighted. In an evaluation of the optimal value of the coefficient of the inverse-distance interpolation scheme, Schierenbeck et al report that the average RMSE calculated for single plants with 15 min values ranges between 6 and 7\% while the interpolation error for a cluster of 140 plants is around $0.9-1.1 \%$ [Schierenbeck et al 2010]. However, the authors only analysed the overall RMSE of the upscaling method and do not analyse the sources of error of the upscaling method. Lorenz et al analysed the effect of the number of reference plants on the regional forecast based on the upscaling method in [Lorenz et al 2009]. It shows that a considerable gain in accuracy is obtained with increasing number of reference plants as long as the number of reference plants is low, and, that this beneficial effect disappears with more than 100 plants for the considered case study. Here, the respective effects of the spatial distribution of the reference plants and the representativeness of the reference plants on the forecasting error are discussed but a systematic analysis of their respective effect is not conducted. The studies mentioned above provide important information on the performances and potential limitations of the upscaling method, but, though the two above-mentioned issues are mentioned, their respective effect on the upscaling error is not explicitly analysed. No further study could be found in the literature where a systematic analysis of the two identified potential sources of error is made and the mechanisms responsible for the uncertainty of the upscaling method are described. The analysis presented in this paper is therefore aimed at filling this gap by analysing in detail the error of the upscaling method using power measurements from a set of $366 \mathrm{PV}$ plants.

The uncertainty of the upscaling error is mainly problematic for grid operations and energy trading issues. For these applications, higher error values are more critical than lower ones. Accordingly, the metric mainly used in this paper to quantify the upscaling error is the root mean square error.

We begin with the principles of the upscaling method in section 2 , and we describe the PV power measurement dataset in section 3. In order to understand the sources of uncertainty resulting from the upscaling method, the analysis of the error is conducted in three steps. Firstly, the interpolation error of single plants is evaluated in section 4, relating the local upscaling error to mismatches between test plants and neighbouring reference plants' parameters or weather conditions. The change of the upscaling error with the aggregation of increasing numbers of test plants is then evaluated in section 5 . Section 6 finally discusses the sensitivity of the upscaling error to the number of reference plants, whereby the effect of the characteristics of the reference plants is also analysed. Section 7 summarizes the results of the paper. 


\section{Principle of the upscaling method}

The basic principle of the upscaling method is to estimate the power generation of a set of un-metered PV plants on the basis of the measurements of a subset of known reference plants using spatial interpolation techniques. The only information systematically available for the unknown plants are the location and the peak capacity.

The first step of the upscaling method consists of normalizing PV-measurements by their nominal capacity so that all yield values (power generation normalized by the nominal capacity) are comparable to each other independent of the respective sizes of the PV plants. The yield of the unknown PV plants is then estimated by spatially interpolating the yield of the reference plants to the location of the unknown plants. Interpolated yield values are then normalized by the nominal capacity of the unknown PV plants and finally aggregated over the considered region to assess the regional PV power generation.

Different interpolation techniques can be used for estimating the unknown yields of plants. In this thesis, the inverse distance weighting (IDW) method has been chosen, as it is frequently used in such applications. The mathematical formulation of this interpolation algorithm is given in equations (2.1) and (2.2) and is illustrated in Figure 1.

The inverse distance weighting [Shepard 1968] is a spatial interpolation method based on the principle that sample values closer to the prediction location have more influence on prediction value than sample values farther apart. A missing value $\mathrm{y}\left(\mathrm{x}_{0}\right)$ at location $\mathrm{x}_{0}$ is calculated by the sum of the known values $y\left(x_{i}\right)$ at locations $x_{i}$ weighted with $a$ coefficient $\mathrm{w}\left(\mathrm{x}_{0}, \mathrm{x}_{\mathrm{i}}\right)$ over all $\mathrm{n}$ known values (Equation 2.1).

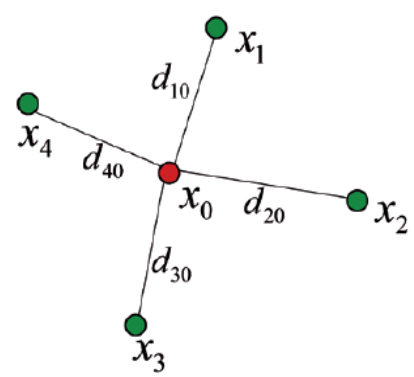

$$
\begin{aligned}
& y\left(x_{0}\right)=\sum_{i=1}^{n} w\left(x_{0}, x_{i}\right) \cdot y\left(x_{i}\right) \\
& w\left(x_{0}, x_{i}\right)=\frac{d\left(x_{0}, x_{i}\right)^{-p}}{\sum_{i=1}^{n} d\left(x_{0}, x_{i}\right)^{-p}} p>0
\end{aligned}
$$

Figure 1: Principle of the IDW spatial interpolation

The weights $w\left(x_{0}, x_{i}\right)$ are evaluated with a decreasing function of the distance $d\left(x_{0}, x_{i}\right)$ between the points $\mathrm{x}_{0}$ and $\mathrm{x}_{\mathrm{i}}$ (Equation 2.2) such that the larger the distance between the point $\mathrm{x}_{\mathrm{i}}$ and $\mathrm{x}_{0}$, the smaller the weight $\mathrm{w}\left(\mathrm{x}_{0}, \mathrm{x}_{\mathrm{i}}\right)$. A value of 1.7 is used for $\mathrm{p}$ in this paper, which has been evaluated in a preliminary analysis and is in good agreement with the results of Schierenbeck [Schierenbeck et al 2010].

\section{Dataset}

The performance of the upscaling method has been evaluated using a set of measurements provided by the German distribution system operator LEW Verteilnetz. This dataset includes 15 min power measurements from $1122 \mathrm{PV}$ plants with a total 
capacity of $511 \mathrm{MW}_{\mathrm{p}}$. A subset of $366 \mathrm{PV}$ plants with a complete and error-free measurements time series on the time period 01/07/2013 - 01/08/ 2014 was selected for the analysis. The spatial distribution of the selected PV plants is shown in Figure 2.

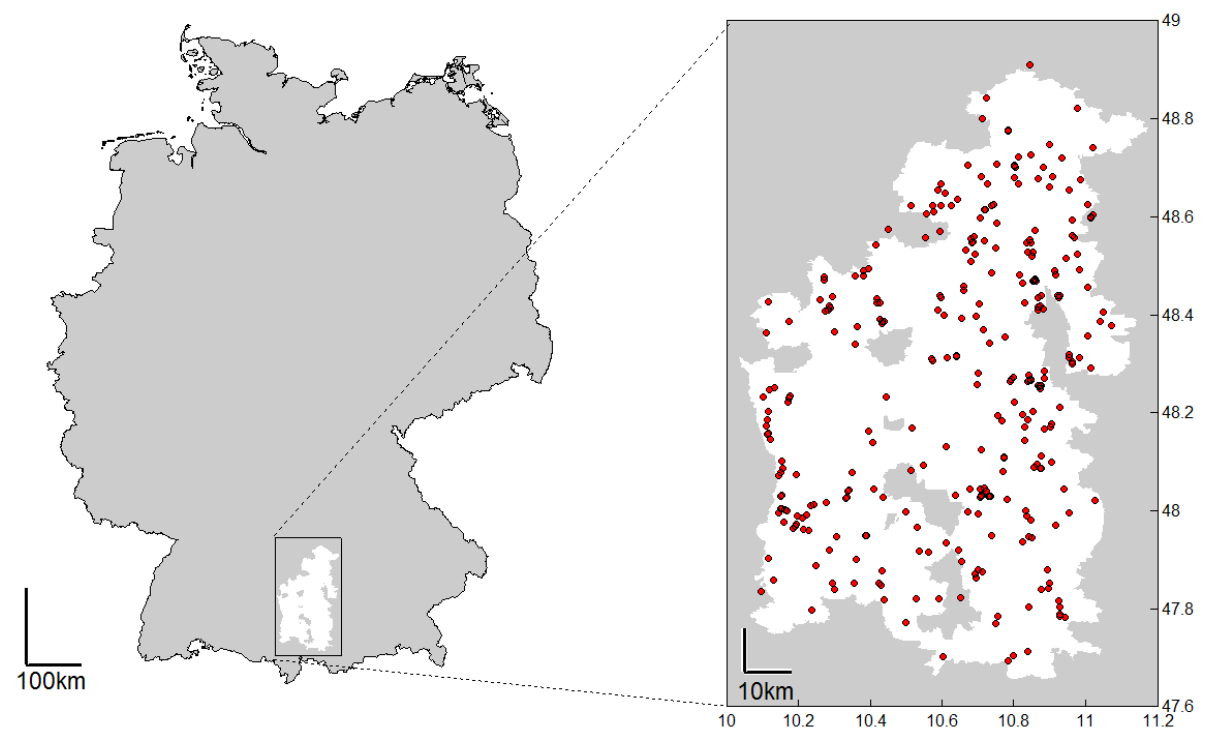

Figure 2: Spatial distribution of the PV plants used in this paper (Source: LEW Verteilnetz).

The probability density distribution of the peak capacity of the plants used for the present analysis is given in Figure 3. The average capacity of the set of plants is equal to $262 \mathrm{kWp}$. The smaller and larger plants have a nominal capacity of $16.65 \mathrm{kWp}$ and $4400 \mathrm{kWp}$ respectively. It can be observed in Figure 3, that the majority of the plants have a nominal capacity larger than $100 \mathrm{kWp}$. The dataset used for this analysis contains thus mainly medium to large plant and small plants are under-represented. The limited representativeness of the dataset with respect to the entireness of the German PV plants is problematic for the generalization of the results presented in this paper. This issue is addressed in section 7.
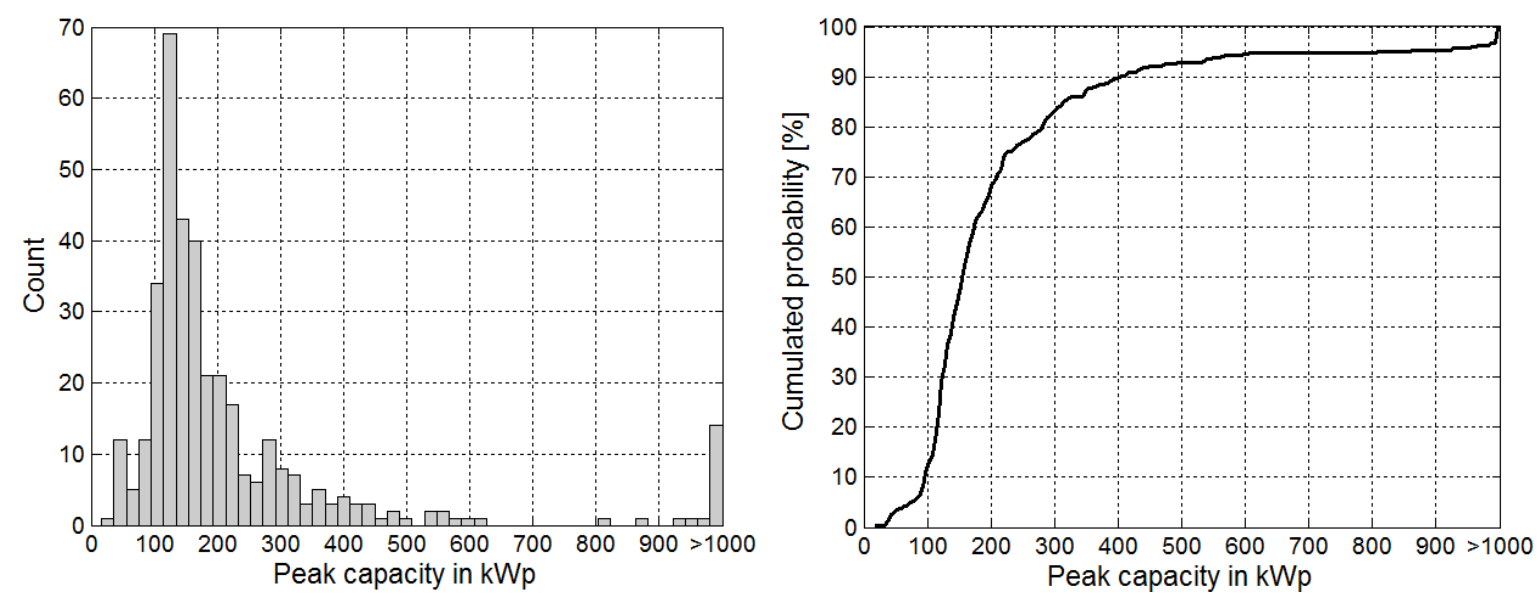

Figure 3: Probability density distribution (left plot) and cumulated probability density (right plot) of the peak capacity of the plants used for the analysis.

\section{Analysis of the interpolation error}

\subsection{Approach}

In this section, the error of the upscaling method for estimating the power generation of a single PV plant is analysed. Using the dataset introduced in the previous section, the 
error of the upscaling method is assessed for each test plant by following the steps below:

1. Split the plants with available measurements into a test and reference set by randomly selecting $15 \%$ of the plants as reference plants.

2. Interpolation of the yield values from the reference plants at the location of the test plants using the upscaling method.

3. Evaluation of the RMSE of the 15 min interpolated yield error at each test plant.

Since the performance of the upscaling method is expected to be dependent on the choice of the set of reference plants, the procedure detailed above is iterated 1000 times. Finally, 311000 RMSE values are obtained (1000 runs with 85\% of the 366 plants).

Once the numerous RMSE values are evaluated, the next step entails conducting a statistical analysis of this data. The analysis is designed to differentiate between the two issues hypothesized to affect performance of the upscaling method: a) the parse sampling of the irradiation field by a limited number of reference PV plants, and b) the variation of the power generation among PV plants due to different PV plant configuration (module orientation, power curve...).

The choice of the analysis-procedure is motivated by two considerations:

- Since meteorological conditions can be expected to be very similar for two neighbour locations, the interpolation error for a small distance between a test and reference plant should solely stem from the parameter-related issue.

- As the distance between a test and reference plant increases, the ability of the interpolation to describe the meteorological conditions at the test plant decreases. In this case, an additional source of error thus affects the performance of the upscaling method: the mismatch between the meteorological data assessed by the reference plants and that present at the test plants.

Based on these considerations, it is reasonable to consider the distance between the test and reference plants while analysing the performance of the spatial interpolation. For the implementation of this conditional evaluation, it remains to assess what distance is the most relevant. Indeed for any test PV plants there is a set of $\mathrm{n}$ distance values corresponding to the $\mathrm{n}$ reference PV plants.

It was chosen to use the minimal distance between a test PV plant and its nearest reference plant. Using only the minimal distance between a test and reference plant is certainly too simple with respect to the spatial nature of the problem. A consideration of further neighbour reference plants would certainly be more appropriate, but it would also significantly increase the complexity of this analysis. It was judged that the gain in accuracy obtained by considering more than one neighbouring reference plant does not justify the involved added cost in complexity.

\subsection{Results}

The results of the 1000 random runs are displayed in the two plots displayed in Figure 4. The same data are displayed in each plot, with a linear scale in left plot and a semi-log scale in the right one. The two representations are given to allow a better visualisation of the fast increase of the RMSE values at small distances. In both plots, RMSE values are 
plotted against the minimal distance to the next reference plant and the colour of the scatter points represents the local point density.

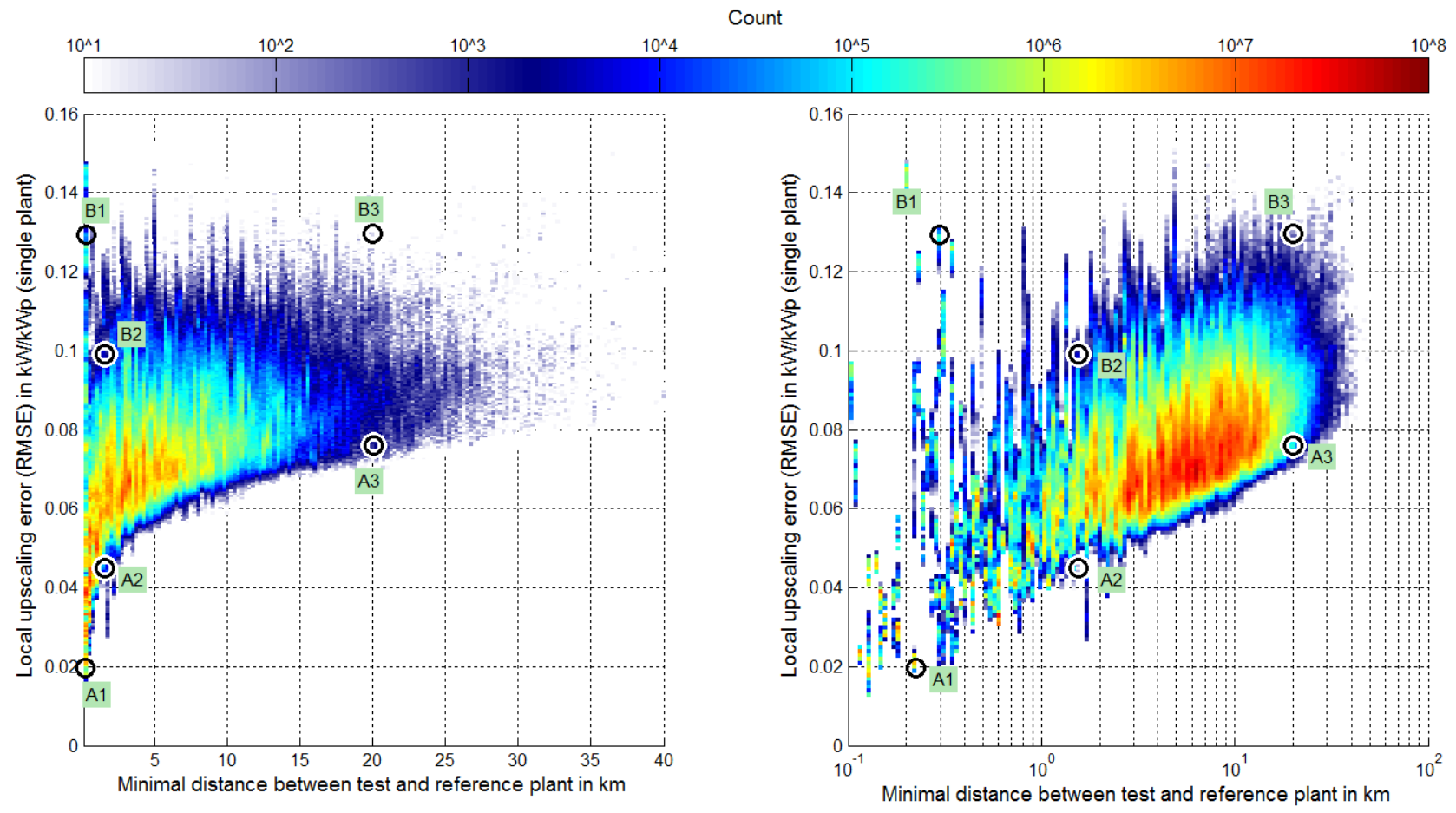

Figure 4: Scatter plot of the interpolation error for single plants (RMSE) as a function of the minimum distance between test and reference plant (left: linear scale - right: semi-log scale). The points A1...A3 and B1...B3 correspond to the runs with the minimal and maximal RMSE values for distances of $200 \mathrm{~m}$, $2 \mathrm{~km}$ and $20 \mathrm{~km}$.

As expected, an augmentation of the upscaling error with increasing distance can be observed in Figure 4. This is particularly remarkable for the minimum values of the error for a given distance from a test plant to its nearest reference plant (lower edge of the cloud of scatter points): minimum values of the upscaling error are equal to around $0.02,0.04,0.06$ and $0.08 \mathrm{~kW} / \mathrm{kW}_{\mathrm{p}}$ at distances equal to $200 \mathrm{~m}, 1 \mathrm{~km}, 10 \mathrm{~km}$ and $30 \mathrm{~km}$ respectively. It can additionally be observed that the RMSE can reach rather high values $\left(0.12-0.15 \mathrm{~kW} / \mathrm{kW}_{\mathrm{p}}\right)$. Such values occur at almost all distances.

At this stage it can be reasonably expected that the minimum value of the upscaling error for a given distance (lower edge of the cloud of scatter points) is reached when the configuration of the test plant is well-matched to the configurations of the surrounding reference plants (the validity of this hypothesis is tested later in this section). Accordingly, it can be hypothesized that the sole effect of the distance between test and reference plants (without the additional error term resulting from the issue of plant configuration) is reflected by these minimum values.

\subsection{Extreme value analysis}

In order to verify the previous conjectures and further understand the sources of error of the upscaling method, a few example plants have been chosen and analysed in more detail. As shortly mentioned before, an in-depth analysis and discussion of all issues affecting the upscaling error would be too exhaustive, due to the variety and complexity of the issues at play. For clarity and conciseness, focus is put on understanding the minimum and maximum RMSE values obtained at three distances $(200 \mathrm{~m}, 2 \mathrm{~km}$ and 20 $\mathrm{km}$ ). These six plants are displayed in Figure 4 separated by error magnitude (A1, A2 and A3 for smaller RMSE values and B1, B2 and B3 for higher RMSE values). The different error metrics corresponding to these 6 examples are given in Table 1. 
Table 1: Different error metrics of the examples $A 1 . . . B 6$ in $\mathrm{kW} / \mathrm{k} W_{p}$

\begin{tabular}{|l|l|l|l|l|l|}
\hline & \multicolumn{1}{|c|}{ RMSE } & \multicolumn{1}{|c|}{ MAE } & \multicolumn{1}{|c|}{ Bias } & \multicolumn{1}{|c|}{$\begin{array}{c}\text { Maximal } \\
\text { positive } \\
\text { error }\end{array}$} & $\begin{array}{c}\text { Maximal } \\
\text { negative } \\
\text { error }\end{array}$ \\
\hline $\mathrm{A} 1(\mathrm{~d}=200 \mathrm{~m})$ & 0.0196 & 0.0117 & 0.0037 & 0.1916 & -0.2751 \\
\hline $\mathrm{B} 1(\mathrm{~d}=200 \mathrm{~m})$ & 0.1290 & 0.0838 & -0.0498 & 0.3933 & -0.6592 \\
\hline $\mathrm{A} 2(\mathrm{~d}=2 \mathrm{~km})$ & 0.0449 & 0.0269 & -0.0159 & 0.4358 & -0.5088 \\
\hline $\mathrm{B} 2(\mathrm{~d}=2 \mathrm{~km})$ & 0.0979 & 0.0635 & -0.0126 & 0.5104 & -0.6224 \\
\hline $\mathrm{A} 3(\mathrm{~d}=20 \mathrm{~km})$ & 0.0750 & 0.0480 & -0.0042 & 0.5056 & -0.5183 \\
\hline $\mathrm{B} 3(\mathrm{~d}=20 \mathrm{~km})$ & 0.1287 & 0.0884 & 0.0346 & 0.6465 & -0.5652 \\
\hline
\end{tabular}

For each of these plants, a scatter plot of the measured power (y-axis) against the interpolated power (x-axis) and a plot of the time series of the measured and interpolated power over two days are provided in Figure 5 and Figure 6. The two days used for the comparison of the time series were chosen so that a broken and a clear-sky condition occur on two consecutive days (05/06/2014-06/06/2014). With this choice, meteorological issues (fluctuations caused by clouds on the power production) and plant characteristics issues (shape of the power production in a cloud-free condition) can be observed.

In order to be able to relate the interpolated yield to the yield of the surrounding reference plants, the distances between each test plant analysed and the next five reference plants as well as their corresponding interpolation weights are given in Table 2 and Table 3.

\section{a) Analysis of examples with a small interpolation error (A1, A2 and A3)}

Before examining the differences between interpolated and measured power time series, it is interesting to compare the weights given by the upscaling method to the 5 nearest reference plants to better understand the characteristics of the interpolated power. For the first example (A1), the next reference plant (225 meter away from the test plant) has a weight of 0.9801 . The interpolated yield is thus almost equal to the yield of the nearest reference plant. The situation is quite similar, albeit to a lower extent, for the second example (A2), where the nearest reference plant ( $2 \mathrm{~km}$ away) has a weight of 0.8103 . The third example (A3) differs noticeably from the first two: the weights of the five next reference plants are much smaller and homogeneous for this plant as compared to the previous ones. This means that for the first two examples, the interpolated yield is almost equal to the measured yield from the nearest available reference plant, while the interpolated yield for the third example is the average yield from several reference plants with relatively even weights. The difference in weight distribution observed for these three plants is likely to affect the characteristics of their interpolated yield.

Table 2: Distance to the next five reference power plants and corresponding weights for the test plants of examples A1, A2 and A3

\begin{tabular}{|c|c|c|c|c|c|}
\hline \multicolumn{2}{|c|}{ Example A1 } & \multicolumn{2}{c|}{ Example A2 } & \multicolumn{2}{c|}{ Example A3 } \\
\hline $\begin{array}{c}\text { Distance } \\
(\mathrm{km})\end{array}$ & $\begin{array}{c}\text { Weight } \\
(-)\end{array}$ & $\begin{array}{c}\text { Distance } \\
(\mathrm{km})\end{array}$ & $\begin{array}{c}\text { Weight } \\
(-)\end{array}$ & $\begin{array}{c}\text { Distance } \\
(\mathrm{km})\end{array}$ & $\begin{array}{c}\text { Weight } \\
(-)\end{array}$ \\
\hline 0,225 & 0,9801 & 2,0547 & 0,8103 & 20,050 & 0,0847 \\
\hline
\end{tabular}




\begin{tabular}{|c|c|c|c|c|c|}
\hline 3,736 & 0,0082 & 10,609 & 0,0307 & 20,995 & 0,0783 \\
\hline 9,631 & 0,0016 & 13,838 & 0,0195 & 23,993 & 0,0624 \\
\hline 9,786 & 0,0016 & 24,420 & 0,0074 & 24,033 & 0,0622 \\
\hline 10,283 & 0,0015 & 24,420 & 0,0074 & 26,373 & 0,0532 \\
\hline
\end{tabular}

In a next step, time series of the measured and interpolated yield are compared for a clear-sky day (2014/06/06 in the right plots from Figure 5) to verify that the characteristics of the reference and test plants are similar (module orientation, power curves...). Indeed, under clear sky conditions, it can be expected that the irradiation and temperature are similar at the test and reference plants. A deviation between the interpolated and measured yield would instead reveal different characteristics between the test plant and its surrounding reference plants. Interpolated power values (red curve) match well with measurements (blue curve) for the three considered plants in clear sky conditions. This confirms the previous conjecture that the error obtained for these examples is relatively little affected by differences in characteristics between test and reference plants (minimal difference can still be observed).

Now that it has been verified for these three examples that the upscaling error is not too affected by a difference in characteristics between test and reference plants, it can be expected that the increase of the RMSE with growing distance stems from differences in irradiation and temperature between the test plants and their surrounding reference plants. To analyse this effect, the measured and interpolated yield are compared on a day marked by the presence of broken clouds (2014/06/05 in right plots from Figure 5). Indeed, broken clouds have a small spatial structure, so that difference in irradiation (and thus in yield) between two neighbouring locations is very likely to occur. In such conditions, it is particularly difficult to interpolate the PV yield and it is therefore easier to observe the upscaling error resulting from different meteorological situations between test and reference plants.

In example A1, the measured and interpolated power values are in very good agreement. The fast fluctuations of the measured and interpolated yield are identical in time and amplitude. Minor differences attributable to very local effects can however be observed, which explain the RMSE value of $0.02 \mathrm{~kW} / \mathrm{kW}_{\mathrm{p}}$. It can in any case be stated that for this first example, no noticeable difference in meteorological condition exists between the test plant and its nearest reference plant. In example A2, the minimal distance to the next reference plant is 10 times greater than in the first example, but still relatively small $(2 \mathrm{~km})$. In contrast to the first example, it can no longer be expected that the meteorological conditions assessed by the reference plant are representative of those prevailing at the test plant, though being quite similar. Indeed, time-series displayed in Figure 5 reveal that the fluctuations present at the reference plant also affect the test plant, with a small difference in amplitude and/or time shift. This difference results in an increased noise in the scatter plot and in a larger interpolation error than in the first example (RMSE $=0.045 \mathrm{~kW} / \mathrm{kW}_{\mathrm{p}}$ for A2 in comparison to $0.02 \mathrm{~kW} / \mathrm{kW}_{\mathrm{p}}$ for A1). These first two examples suggest a possible explanation for the exponential shape of the RMSE with the distance observed in Figure 4. Indeed, the fast increase of the interpolation error with the distance at low separation may be attributed to fast fluctuations resulting from local clouds, which become out of phase at two neighbouring locations, even if the distance between them is small. 
In example $A 3$, the minimal distance between the test and reference plants is no longer small $(20 \mathrm{~km})$. As previously mentioned, the interpolated power is no more predominantly influenced by one plant, as before, but rather by several plants located relatively far from the test plant (20 to $30 \mathrm{~km}$ ). This results in an interpolated power that is much smoother than that observed in the two previous examples (lower right plot in Figure 5). In this example, the relatively high value of the upscaling error is principally due to the fact that the fast fluctuations present in the measurements of the test plant are absent in the interpolated power, which is a result of the above-mentioned smoothing.

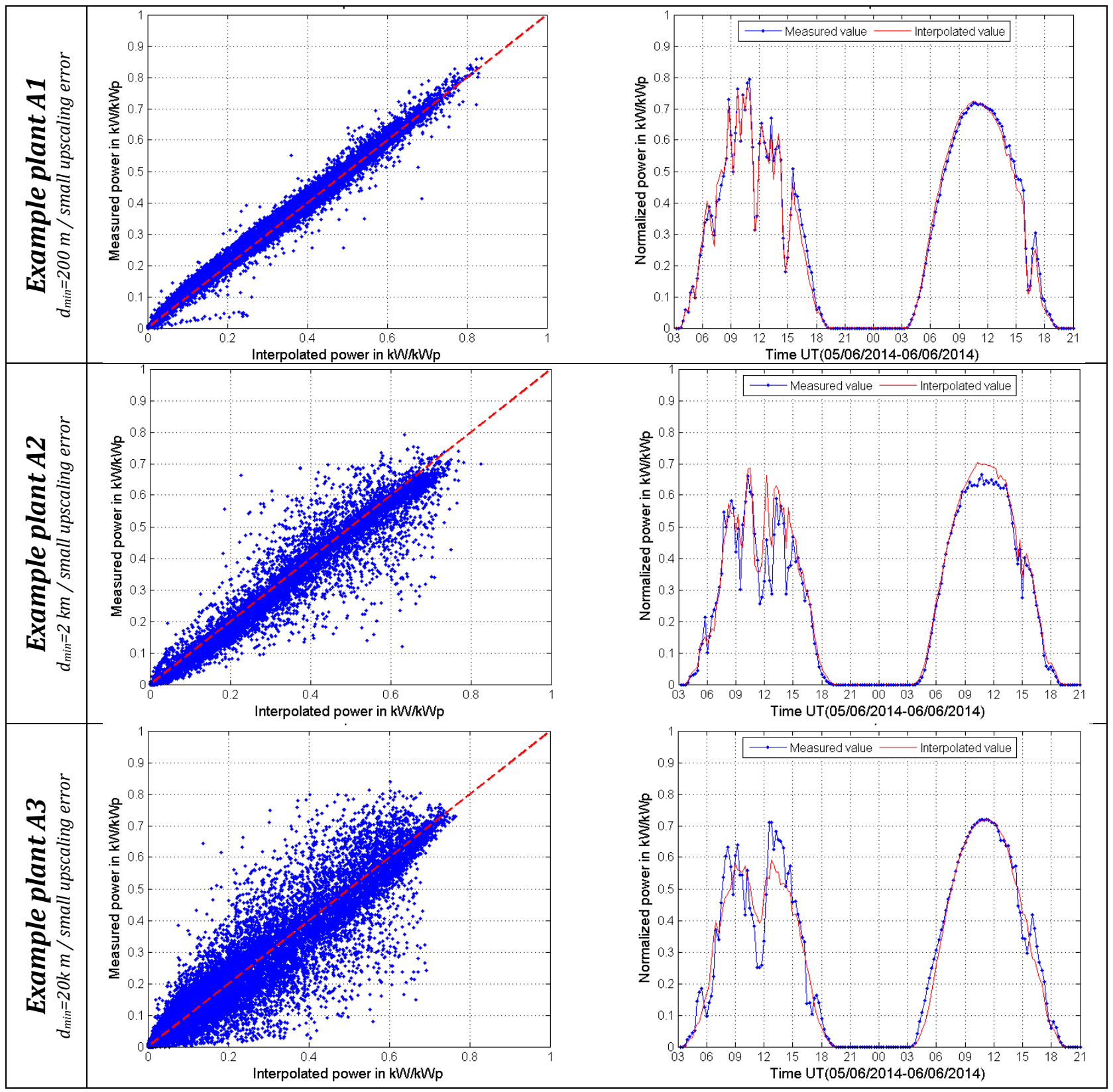

Figure 5: Comparison of measurements with interpolated data for the examples A1, A2 and A3 - left: scatter plot of the measured yield ( $\mathrm{y}$-axis) as a function of the interpolated yield ( $\mathrm{x}$-axis); right: time series plot of the measured (blue curve) and interpolated yield (red curve) over two days (05/06/2014 $06 / 06 / 2014$ )

b) Analysis of examples with a high interpolation error (B1, B2 and B3) 
The weights in examples B1 and B2 (Table 3) are very similar to those found in examples A1 and A2. In example B3, the upscaling method weights two reference plants with coefficients of 0.2549 and 0.1527 , while further plants are weighted with coefficients of similar magnitude approximately equal to 0.06 .

Table 3: Distance to the next five reference power plants and corresponding weights for the test plants of examples B1, B2 and B3

\begin{tabular}{|c|c|c|c|c|c|}
\hline \multicolumn{2}{|c|}{ Example B1 } & \multicolumn{2}{c|}{ Example B2 } & \multicolumn{2}{c|}{ Example B3 } \\
\hline $\begin{array}{c}\text { Distance } \\
(\mathrm{km})\end{array}$ & $\begin{array}{c}\text { Weight } \\
(-)\end{array}$ & $\begin{array}{c}\text { Distance } \\
(\mathrm{km})\end{array}$ & $\begin{array}{c}\text { Weight } \\
(-)\end{array}$ & $\begin{array}{c}\text { Distance } \\
(\mathrm{km})\end{array}$ & $\begin{array}{c}\text { Weight } \\
(-)\end{array}$ \\
\hline 0,298 & 0,9644 & 2,049 & 0,8254 & 20,020 & 0,2549 \\
\hline 3,557 & 0,0142 & 12,864 & 0,0226 & 27,068 & 0,1527 \\
\hline 6,405 & 0,0052 & 13,853 & 0,0199 & 44,019 & 0,0668 \\
\hline 7,350 & 0,0041 & 14,553 & 0,0183 & 44,193 & 0,0663 \\
\hline 9,293 & 0,0028 & 14,975 & 0,0174 & 48,265 & 0,0571 \\
\hline
\end{tabular}

Figure 6 shows that the observations made for examples A1, A2 and A3 are also valid at $\mathrm{B} 1, \mathrm{~B} 2$ and B3. These are however of minor importance in comparison to an obvious difference in the module orientation (and eventually in the power curve) between the test plants and their surrounding reference plants. This difference can first be observed in the time series plot (right pictures in Figure 6), where an increase (or decrease) in the measured yield occurs earlier (example B3) or later (examples B1 and B2) than for the interpolated yield. This result is typical when there is a difference in module azimuth angle between two plants. Additionally, differences in the daily maximum between measured and interpolated yield suggests that the tilt angle or the power curves of the PV plants are different. These differences are also obvious in the left pictures from Figure 5, where scatter points are not aligned along the identity line and instead form an ellipse.

The three examples displayed in Figure 6 show that differences in characteristics between the test and its surrounding reference plants are responsible for the large value of the RMSE. A visual inspection of other test plants with large RMSE confirmed that this issue explains larger interpolation errors.

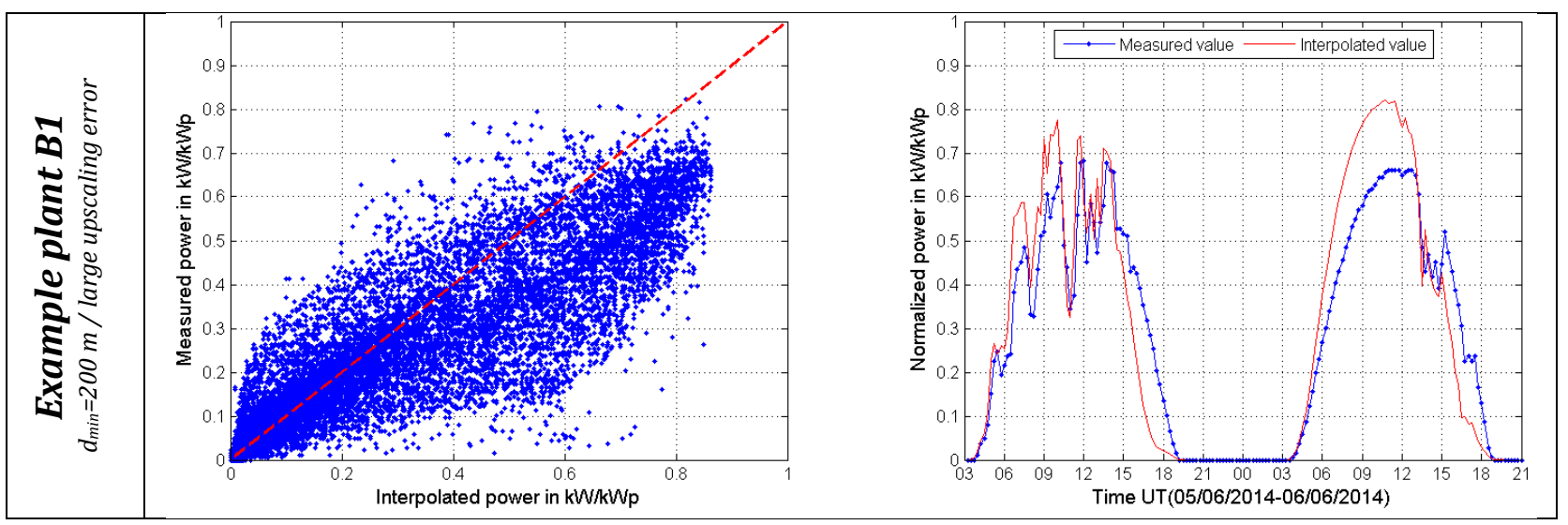




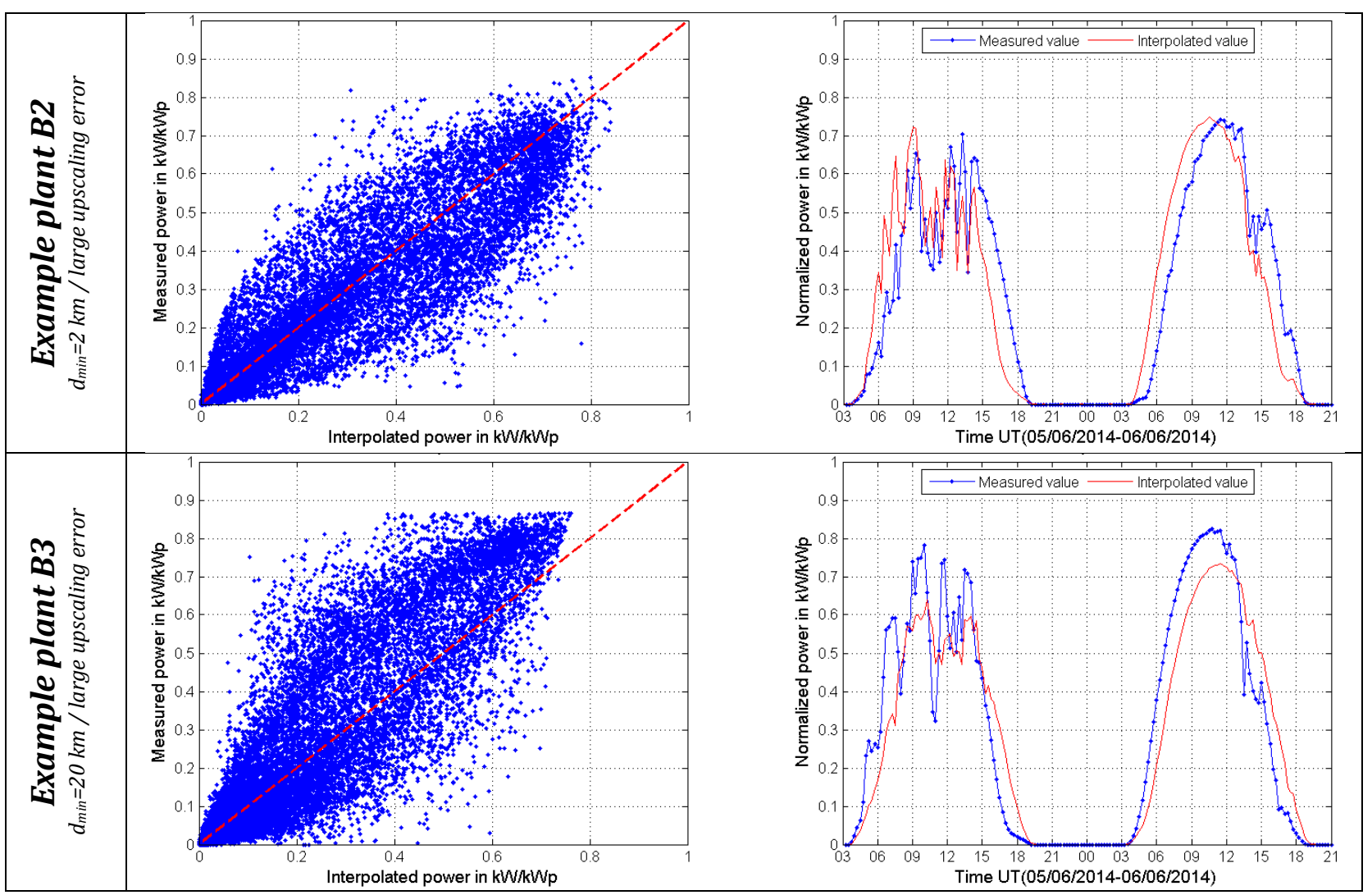

Figure 6: Comparison of measurements with interpolated data for the examples B1, B2 and B3 - left: scatter plot of the measured yield ( $\mathrm{y}$-axis) as a function of the interpolated yield ( $\mathrm{x}$-axis); right: time series plot of the measured (blue curve) and interpolated yield (red curve) over two days (05/06/2014 06/06/2014)

The analysis described in this section confirms that two issues degrade the local performance of the upscaling method. Firstly, differences in meteorological data between test and reference plants result in an exponential growth of the RMSE. It was found that the differences in characteristics (e.g. module orientation, power curve) between test and reference plants were systematically responsible for larger errors. This second issue can results in values of the RMSE greater than $0.15 \mathrm{~kW} / \mathrm{kW}_{\mathrm{p}}$ for all distances between test and reference plants. A visual inspection of PV plants with intermediate RMSE values (greater than the minimum and smaller than the maximum values analysed in the six examples) also revealed the effects previously described though at different degrees.

\section{Analysis of the effect of plant aggregation on the interpolation error}

In the previous section, the error of the spatial interpolation has been analysed. This approach was chosen to facilitate the understanding of the mechanisms impacting the interpolation error. However, the interpolation error for a single plant is very different to that found for a cluster of PV plants. Schierenbeck reported that the average RMSE for single plants ranges between 6 and 7\% while the interpolation error for a cluster of 140 plants is around $0.9-1.1 \%$ [Schierenbeck et al 2010]. A very different order of magnitude for the error is thus found when considering a single plant as compared to the aggregated power of a set of PV plants. As a result, though they give insight into the processes responsible for the interpolation error, the results obtained in the previous 
analysis are of limited relevance for the assessment of the PV power generated in a region.

\subsection{Approach}

In order to analyse the decrease of the interpolation error by the clustering of PV plants, one run has been chosen among the 1000 random runs realized in the previous section (the difference between the run being the set of reference PV plants). Since only one run is analysed in this section, it was decided to choose a run with a performance close to the average performance of the 1000 runs. For this run the total set of plants $\left(S_{0}\right)$ is divided in two complementary subsets of test and reference plants $S_{\text {test }}$ and $S_{\text {ref }}$ $\left(S_{\text {test }} \cup S_{\text {ref }}=S_{0}\right.$ and $\left.S_{\text {test }} \cap S_{\text {ref }}=\emptyset\right)$.

The effect of PV plant aggregation on the spatial error is then evaluated for a cluster of $\mathrm{n}$ test plants $\tilde{S}_{\text {test }}$ taken randomly from the set $S_{\text {test }}\left(\tilde{S}_{\text {test }} \subset S_{\text {test }}\right)$ by following the four steps:

- Power measurements of the $\mathrm{n}$ test plants are summed to evaluate the total PV power generation of the considered cluster

- Interpolated yield values of the $n$ test PV plants are evaluated with the upscaling method, normalized by their nominal capacity and summed.

- The difference between the aggregated measurements and their estimates from the upscaling method is evaluated at each time step

- The RMSE of the upscaling method is finally calculated for the $\mathrm{n}$ test plants with the 15 min time series of the error evaluated above

For each subset of PV plant $S_{\text {test }}$ from the initial set $S_{0}$, the RMSE value is thus found from the power measurements $P_{\text {meas }, i}(t)$ and the interpolated power values $P_{i d w, i}\left(S_{r e f,} t\right)$ at each test plant $i$ of $S_{\text {test }}$ using measurements of the set of reference plants $S_{\text {ref }}$ at each time $t$ $\left(\mathrm{t}=1 \ldots \mathrm{N}_{\mathrm{t}}\right)$ with the following relation:

$\operatorname{RMSE}\left(\tilde{S}_{\text {test }}\right)=\sqrt{\frac{1}{N_{t}} \sum_{t=1}^{N_{t}}\left[\left(\sum_{i \in \tilde{S}_{\text {test }}} P_{\text {meas }, i}(t)-\sum_{i \in \tilde{S}_{\text {test }}} P_{\text {idw }, i}\left(S_{\text {ref }}, t\right)\right)^{2}\right]} \begin{aligned} & \tilde{S}_{\text {test }} \subset S_{\text {test }} \\ & S_{\text {test }} \cup S_{\text {ref }}=S_{0} \\ & S_{\text {test }} \cap S_{\text {ref }}=\varnothing\end{aligned}$

This procedure is conducted for sets including 1 to $311 \mathrm{PV}$ plants (total number of test plants) in order to assess the effect of the number of aggregated plants on the upscaling error. As it can be expected that the results of this experiment depends on the choice of the aggregated plants, for each aggregation size, the set of test plants has been randomly chosen 1000 times. The results are then normalized to the total installed capacity of the set of PV plants so that the different results can be compared independently from the total capacity of the group considered.

The assessment described above was conducted for two configurations. In a first step, all test PV plants were assumed to have the same installed capacity. In the second step, the actual capacities of the test plant were considered. The motivation for the choice of these two configurations is described later in this section. 


\subsection{Results}

The results of the calculations are illustrated in Figure 7. In both plots, RMSE values obtained with the upscaling method are represented as a function of the number of plants aggregated together. In the left plot, the results obtained when the nominal capacity of all plants is assumed to be identical are represented. Error values evaluated with consideration of the actual nominal capacity of the test PV plants are displayed in the right picture.

The two plots displayed in Figure 7 confirm the statement of Schierenbeck et al that the RMSE of the spatial interpolation decreases as the number of aggregated PV plants increases. A fast reduction can be observed as the number of aggregated PV plants increases from 1 to 50 and the gain in accuracy is much smaller for any further increase of the number of aggregated PV plants.
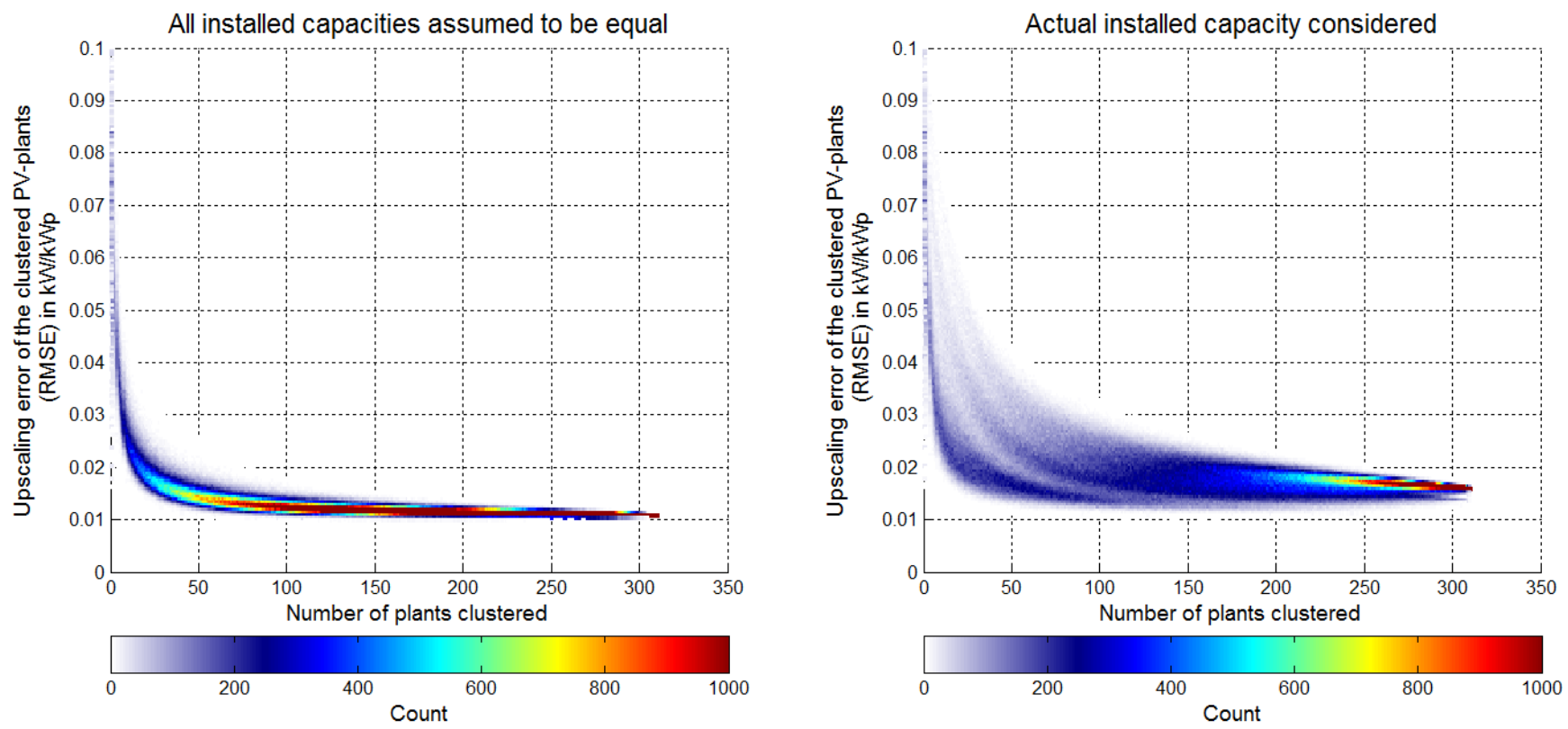

Figure 7: Scatter plot of the spatial interpolation error (y-axis) for $\mathrm{N}$ aggregated power measurements (N is on the x-axis) Left picture: all plants are assumed to have the same capacity. Right picture: consideration of the actual capacity of the test plants

The dispersion of the scatter points is very different for the two experiments. For a given cluster size, the dispersion of the RMSE values is much larger when the actual nominal capacities of PV plants is considered (right plot) than when all nominal capacities are assumed to be equal (left plot). The decrease of the RMSE values with the number of aggregants under the assumption of an equal capacity for all plants is analysed in the following subsection, after which the impact of the actual nominal capacity on the decrease of the RMSE is investigated and discussed.

\section{a) Analysis of the RMSE reduction assuming equal plant capacities}

The decrease of the RMSE values with increasing number of reference plants observed in Figure 7 is in good agreement with the results presented by Lorenz et al. in [Lorenz et al 2010].

In the calculation presented in this section, the RMSE values are calculated with the mean error of samples of test plants randomly selected from a population of 311 test 
plants. With this formulation, it clearly follows that the central limit theorem applies under the condition that the samples are independent. Accordingly, for each time step, the distribution of the average error converges to a normal distribution with a variance $\sigma_{0}^{2}(t) / N$ and mean $\mu_{0}(t)$, where $\sigma_{0}^{2}(t)$ and $\mu_{0}(t)$ are the variance and mean of the original population at time $t$ and $N$ is the number of aggregated samples. Since, the distribution of samples error is a normal distribution, the mean square error - or second moment of the normal error distribution - is equal to $\left(\sigma_{0}^{2}(t) / N+\mu_{0}^{2}(t)\right)$ and the RMSE can be expressed as:

$R M S E=\sqrt{\frac{1}{N_{t}} \sum_{t=1}^{N_{t}}\left(\frac{\sigma_{0}^{2}(t)}{N}+\mu_{0}^{2}(t)\right)}$,

Where $\mathrm{N}$ is the number of samples, $\mathrm{N}_{\mathrm{t}}$ is the number of time steps and $\sigma_{0}(t)$ and $\mu_{0}(t)$ are the standard deviation and the mean error of the original population at time $t$, respectively.
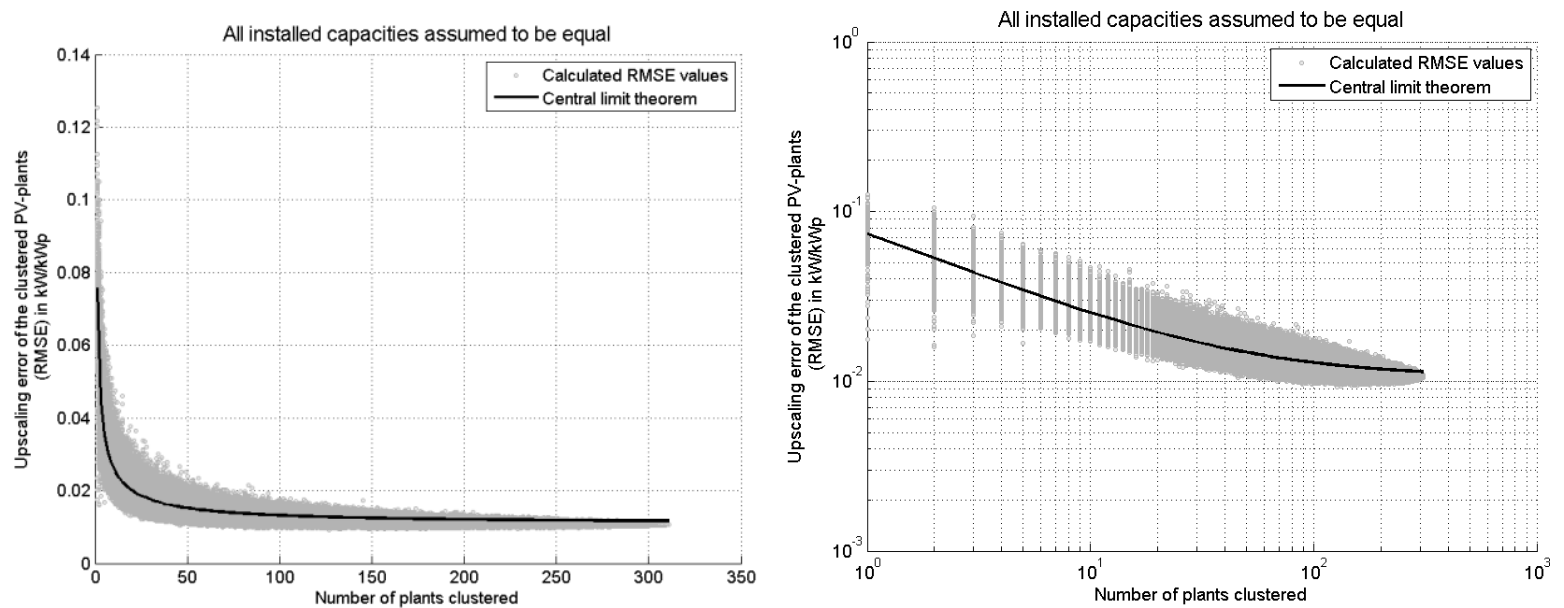

Figure 8: Comparison of the aggregated spatial interpolation error (RMSE) obtained by assuming all installed capacities equal (grey dots) with the theoretical dependency of the RMSE on the number of aggregates as derived from the central limit theorem (black curve) - Left picture: results displayed in a linear scale. Right picture: results displayed in a log-log scale.

In order to verify whether the central limit theorem can explain the results displayed in the left graphic of Figure 7, RMSE values obtained from the different aggregations (grey dots) are compared to the expected decrease of the RMSE with the number of aggregates according to Eq. 4.1 (black curve) in Figure 8. The good agreement between the scatter points and the black line shows that the decrease of the RMSE observed in Figure 7 and 8 can be explained by the central limit theorem. This process results from the independence of individual error terms with different magnitudes and opposite signs that may cancel. This error balancing of two terms with opposite sign may for example occur in the two following cases:

- Two plants with both over- and underestimated yields experience a heterogeneous weather situation. This can happen when one plant is under clearsky conditions, while its reference plants are shaded by clouds, and vice versa for the second plant.

- Two plants have local upscaling errors of opposite sign due to particular plant configurations. For example, the power of a PV plant can be underestimated in the afternoon because it is more oriented to the west than its surrounding 
reference plants, while the output of another plant is overestimated because it is more oriented to the east than its reference plants.

The local variance of the upscaling error is thus resulting from the irradiation variability and a variability resulting from spatial variations of plants characteristics. The irradiation and PV power output variability has been the subject of several studies [Hoff et Perez 2010], [Hoff et Perez 2012] [Perez et al 2015] [Remund et al 2015]. In contrast, the spatial differences of PV plants configuration and their effect on regional upscaling or forecast have been little investigated so far.

\section{b) Analysis of the RMSE reduction considering the actual plant capacities}

The noticeable difference between results obtained by assuming that all plants have the same size and when the actual nominal capacity is considered remains to be explained. The only difference between these two calculations is the weight given to yield values from individual plants. In the first case all weights are assumed equal and in the second case the weights are proportional to the nominal capacity. Larger error values obtained in the second calculation can thus be explained by above-average weights given to large plants with high local upscaling error and below-average weights given to small plants with small local upscaling error.

The difference between the results from the two experiments is very interesting as it gives insight regarding issues to be considered in the choice of the set of reference plants needed to limit the upscaling error. Indeed, a pragmatic way to limit the upscaling error is to choose the set of reference plants so that the error at large plants is minimal (due to the above-average influence of these plants on the total upscaling error).

\section{Influence of the set of reference plants on the upscaling error}

One last issue remains to be addressed to complete the analysis of the upscaling error: the influence of the set of reference plants on the upscaling error. Indeed, on the basis of the previous analysis, it can be expected that not only the number of reference plants, but also their spatial distribution and characteristics impact the upscaling error.

\subsection{Approach}

In order to analyse the effect of the set of reference plants on the total upscaling error, the same procedure as that used in previous sections is implemented (under consideration of the actual capacity). The available plants are first randomly split into a set of reference plants and a set of test plants. The total power of the set of test plants is then evaluated with the upscaling method on the basis of the power measurements from the reference plants. The skill of the upscaling method is finally assessed with the set of test plants by calculating the RMSE between aggregated measurements and the results of the upscaling method.

In contrast to the analysis conducted in section 5 , where the set of reference plants was fixed and a subset of the test plants was considered, in this section the set of reference plants is varying and the complete set of test plants is considered. Using the notation introduced in section 5, the RMSE is calculated for a set of reference plants $S_{\text {ref }}$ randomly chosen in the total set of plants $S_{0}$ using the set of test plants $S_{\text {test }}$ using the following relation: 
$\operatorname{RMSE}\left(S_{\text {test }}\right)=\sqrt{\frac{1}{N_{t}} \sum_{t=1}^{N_{t}}\left[\left(\sum_{i \in S_{\text {test }}} P_{\text {meas }, i}(t)-\sum_{i \in S_{\text {test }}} P_{\text {idw }, i}\left(S_{\text {ref }}, t\right)\right)^{2}\right]} \begin{aligned} & S_{\text {test }} \subset S_{0} \\ & S_{\text {test }} \cup S_{\text {ref }}=S_{0} \\ & S_{\text {test }} \cap S_{\text {ref }}=\varnothing\end{aligned}$

The sets of test and reference plants are distinct, such that reference plants are excluded from the data used for the evaluation of the RMSE. Therefore, as the number of reference plants increases, the number of test plants used for the evaluation of the upscaling RMSE decreases (the number of test plants used for the assessment of the RMSE is displayed on the upper x-axis of Figure 9). In a strict sense, RMSE values obtained with sets of reference plants of different sizes should not be compared since, as shown previously, the number of aggregated plants influences the upscaling error. However, as can be observed in Figure 7, the influence of the number of test plants on the upscaling error is relatively limited when more than 200 test plants are used. The maximal number of reference plants is thus limited to 100 so that the number of test plants remains larger than 266. With this precaution, RMSE values obtained from sets of reference plants with difference sizes will be compared regardless of this issue for the remainder of this analysis.

To assess the effect of the size of the set of reference plants on the performance of the upscaling method, the calculation is conducted using sets of reference plants including one to 100 plants (one third of the available set). Since a particular choice of the set of reference PV plants may affect the performance of the upscaling method, the procedure is iterated 1000 times for each considered number of reference plants.

\subsection{Results}

The RMSE values obtained for the different sets of reference plants are displayed as a function of the number of reference plants in Figure 9. As expected, the error decreases steadily with the number of reference plants used for the upscaling. This decrease is very strong for up to 20 reference plants, before diminishing. A saturation in the reduction of the RMSE with the number of reference plants occurs when more than 70 reference PV plants are used. With more than 70 reference PV plants, RMSE values range from 0.009 to $0.022 \mathrm{~kW} / \mathrm{kW}_{\mathrm{p}}$ and most observed RMSE values lie in the interval 0.01 $0.015 \mathrm{~kW} / \mathrm{kW}_{\mathrm{p}}$ (red scatter points). 


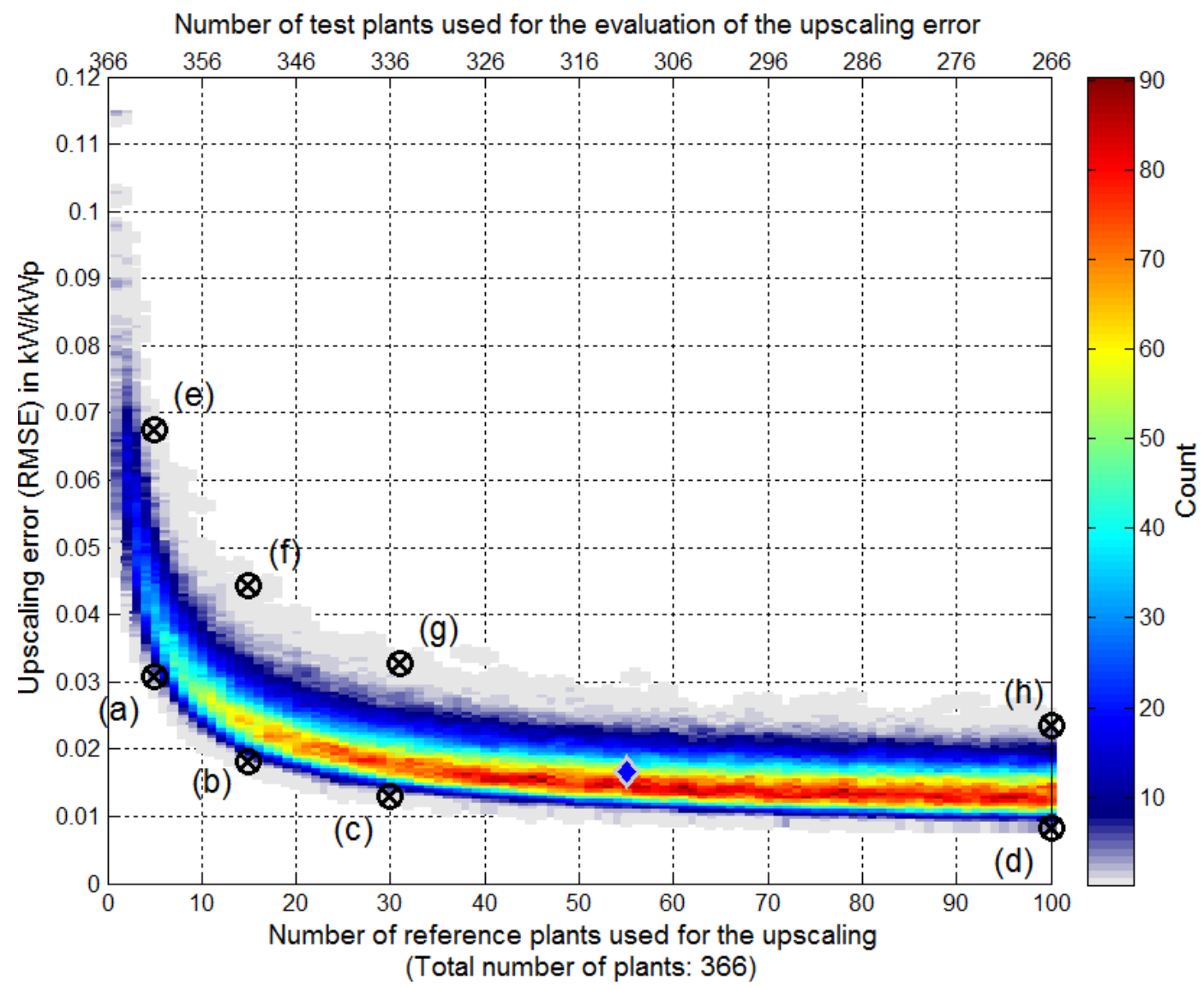

Figure 9: Upscaling error as a function of the number of reference plants used for the upscaling. The number of reference plants is displayed on the lower abscissa and the number of test plants on the upper abscissa. The points (a)...(d) and (e)...(h) corresponds to the minimal and maximal RMSE values for 5, 15, 30 and 100 reference plants respectively. The blue diamond represents the run analysed in section 5 .

It is interesting to observe in Figure 9, that a low RMSE values can already be obtained with 30 reference plants $(0.013 \mathrm{~kW} / \mathrm{kWp})$, which is comparable with those corresponding to 100 reference plants. In addition, even with a large number of reference plants (100 reference plants), there is a relatively high variation of the RMSE values $(0.008-0.026 \mathrm{~kW} / \mathrm{kWp})$. It can be expected that these features are resulting from the characteristics of the set of reference plants: on the one hand the spatial distribution of the reference plants and on the other hand the similarity between the characteristics of the reference and test plants. In order to further analyse the role of the characteristics of the set of reference plants, the set corresponding to the lower and higher RMSE values for set of reference plants with 5, 1530 and 100 plants are further analysed in the continuation of this section. These examples are marked in Figure 9 and their main characteristics are summarized in Tables 4 and 5. In addition, the spatial distribution of the reference and test plants as well as the scatter plots of the aggregated measurements against upscaling estimates are given in the plots of figure 11.

Table 4: Different error metrics of the example (a)....(h) in $k W / k W_{p}$.

\begin{tabular}{|c|c|c|c|c|c|}
\hline & RMSE & MAE & Bias & $\begin{array}{c}\text { Maximal } \\
\text { positive } \\
\text { error }\end{array}$ & $\begin{array}{c}\text { Maximal } \\
\text { negative } \\
\text { error }\end{array}$ \\
\hline (a) & 0.0308 & 0.0187 & -0.0018 & 0.2348 & -0.2610 \\
\hline (b) & 0.0181 & 0.0118 & -0.0006 & 0.1293 & -0.1391 \\
\hline (c) & 0.0131 & 0.0082 & -0.0009 & 0.1174 & -0.0899 \\
\hline
\end{tabular}




\begin{tabular}{|c|c|c|c|c|c|}
\hline (d) & 0.0083 & 0.0051 & -0.0009 & 0.0640 & -0.0642 \\
\hline (e) & 0.0676 & 0.0472 & -0.0437 & 0.1499 & -0.2779 \\
\hline (f) & 0.0443 & 0.0300 & -0.0166 & 0.1606 & -0.3677 \\
\hline (g) & 0.0328 & 0.0224 & -0.0186 & 0.1094 & -0.1599 \\
\hline (h) & 0.0235 & 0.0152 & -0.0113 & 0.0510 & -0.1285 \\
\hline
\end{tabular}

To quantify the match between the spatial aggregation of the reference and set plants, the average distance between reference and test plants is given in addition to the RMSE in Table 5. Based on the analysis presented in Section 2, it is defined as the average value of the minimal distances to the next reference plant weighted by the peak capacity of the test plants:

$\bar{d}_{\text {ref-test }}=\frac{\sum_{i=1}^{N_{\text {test }}} P_{\text {peak }, i} \cdot \min \left\{d_{i j}, j=1 \ldots N_{\text {ref }}\right\}}{\sum_{i=1}^{N_{\text {test }}} P_{\text {peak }, i}}$

Where:

The indices $\mathrm{i}$ and $\mathrm{j}$ refer to the test and reference plants respectively

$\mathrm{N}_{\text {test }}$ and $\mathrm{N}_{\text {ref }}$ are the number of test and reference plants.

$\mathrm{d}_{\mathrm{ij}}$ is the distance between the test plant $\mathrm{i}$ and the reference plant $\mathrm{j}$.

$\mathrm{P}_{\text {peak,j }}$ is the peak capacity of the test plant $\mathrm{i}$.

Table 5: Main characteristics of the eight set of reference plants considered for the analysis of the effect of the reference plants on the upscaling error

Lower RMSE values

\begin{tabular}{|c|c|c|c|}
\hline & $\begin{array}{c}\text { Number } \\
\text { of } \\
\text { reference } \\
\text { plants }\end{array}$ & $\begin{array}{c}\text { Mean } \\
\text { distance } \\
{[\mathrm{km}]}\end{array}$ & $\begin{array}{c}\text { RMSE } \\
{\left[\mathrm{kW} / \mathrm{kW}_{\mathrm{p}}\right]}\end{array}$ \\
\hline (a) & 5 & 15.3 & 0.0308 \\
\hline (b) & 15 & 10.1 & 0.0181 \\
\hline (c) & 30 & 6.5 & 0.0131 \\
\hline (d) & 100 & 3.7 & 0.0083 \\
\hline
\end{tabular}

Higher RMSE values

\begin{tabular}{|c|c|c|c|}
\hline & $\begin{array}{c}\text { Number } \\
\text { of } \\
\text { reference } \\
\text { plants }\end{array}$ & $\begin{array}{c}\text { Mean } \\
\text { distance } \\
{[\mathrm{km}]}\end{array}$ & $\begin{array}{c}\mathrm{RMSE} \\
{\left[\mathrm{kW} / \mathrm{kW}_{\mathrm{p}}\right]}\end{array}$ \\
\hline (e) & 5 & 18.8 & 0.0676 \\
\hline (f) & 15 & 19.9 & 0.0443 \\
\hline (g) & 30 & 8.1 & 0.0328 \\
\hline (h) & 100 & 3.4 & 0.0235 \\
\hline
\end{tabular}

It can be observed in Table 5 , that the average distance decreases with increasing number of reference plants. For a given number of reference plants, the average distances are generally higher in the examples corresponding to high RMSE values (right table) than those corresponding to low RMSE values (left table). This is plausible considering that the interpolation error increase with the distance to the reference plants. Based on these observations, it is legitimate to question whether the average distance introduced in equation 6.2 is not a better indicator for the analysis of the performance of the upscaling error than the number of reference plants. To verify this hypothesis, the RMSE values displayed in Figure 9 are represented as a function of the average distance in Figure 10. 


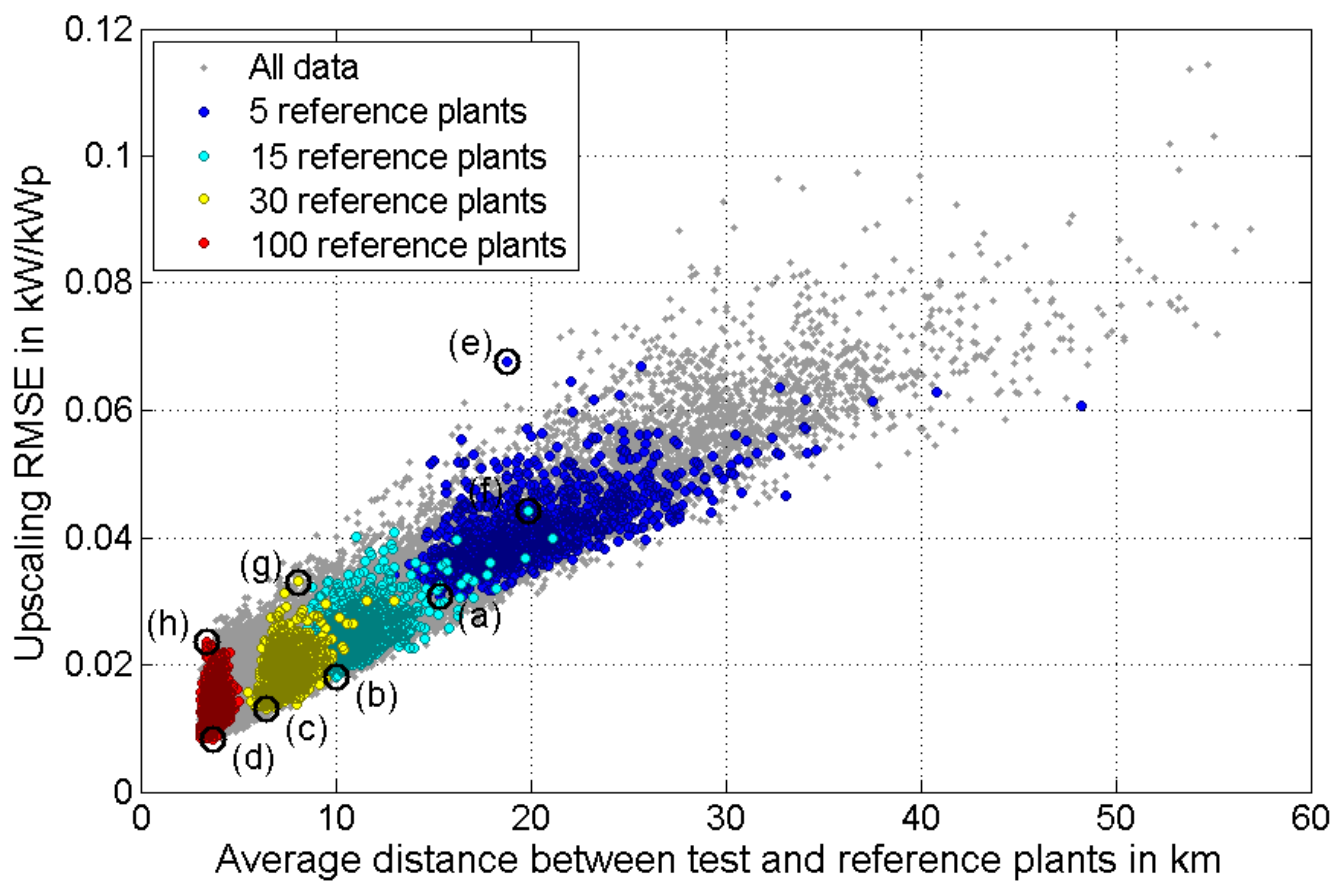

Figure 10: Upscaling error as a function of the average distance between test and reference plants. The points (a)...(d) and (e)...(h) corresponds to the minimal and maximal RMSE values for 5, 15, 30 and 100 reference plants respectively (see Figure 9).

In Figure 10, the RMSE values corresponding to 5, 15, 30 and 100 reference plants are displayed by coloured dots and the eight examples previously introduced are marked by black circles.

The clear dependency between RMSE values and average distance in Figure 10 confirms that the average distance represents a better indicator of the performances of the set of reference plants than their number. This is normal since the quantity of reference plants is not a guarantee that all test plants are well described by the reference plants. Instead the average value represents a more reliable measure of the quality of the set of reference plants.

Examples (a), (b), (c) and (d) lie on the lower limit of the scatter points of Figure 10. The scatter points given in Figure 11 show that the scatter points are centred on the identity line for these 4 examples and that the increase of the RMSE values result from a rise of the point dispersion. Considering the results presented in section 2, it appears reasonable to consider that there is a good match between the characteristics of the test and reference plants for these four examples and that the increase in RMSE from example (a) to (d) is due to increasing difference in meteorological conditions between test and reference plants increasing as the average distance gets higher. The scatter points displayed in Figure 11 reveal that the larger RMSE values of the examples (e), (f), $(\mathrm{g})$ and $(\mathrm{h})$ are clearly resulting from a mismatch between the test and reference plants (the scatter points are not centred on the identity line). The lower bound of the scatter points in Figure 10 corresponds thus to set of reference plants with a very good match between test and reference plants, while higher RMSE values result from a mismatch between the characteristics of reference and test plants. 
(a) 5 reference plants, RMSE $=0.0308 \mathrm{~kW} / \mathrm{kWp}$

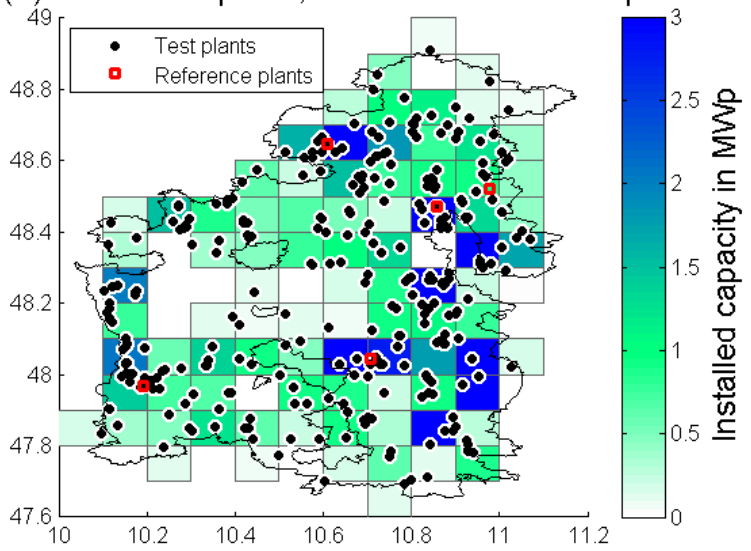

(e) 5 reference plants, RMSE $=0.0676 \mathrm{~kW} / \mathrm{kWp}$

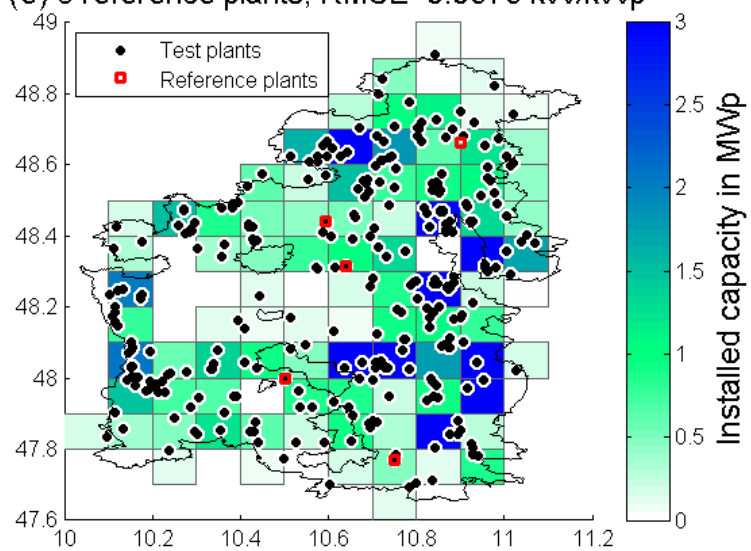

(b) 15 reference plants, RMSE $=0.0181 \mathrm{~kW} / \mathrm{kWp}$

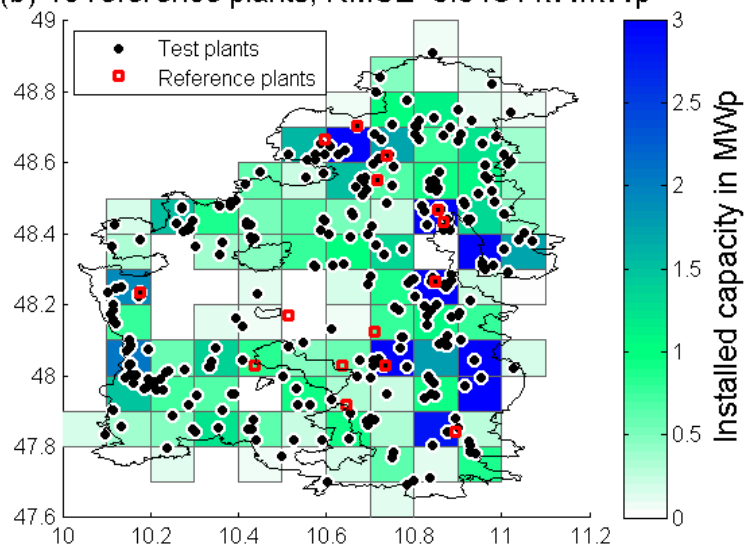

(f) 15 reference plants, RMSE $=0.0443 \mathrm{~kW} / \mathrm{kWp}$

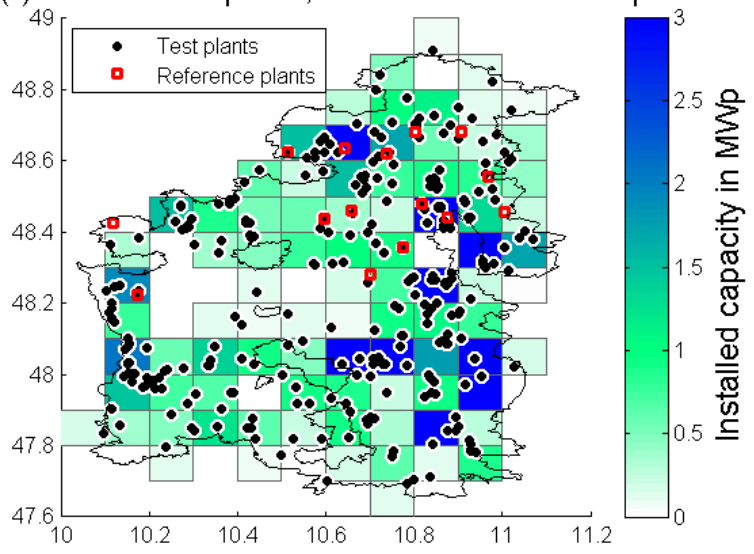

Preprint submitted to Solar Energy in January 2016

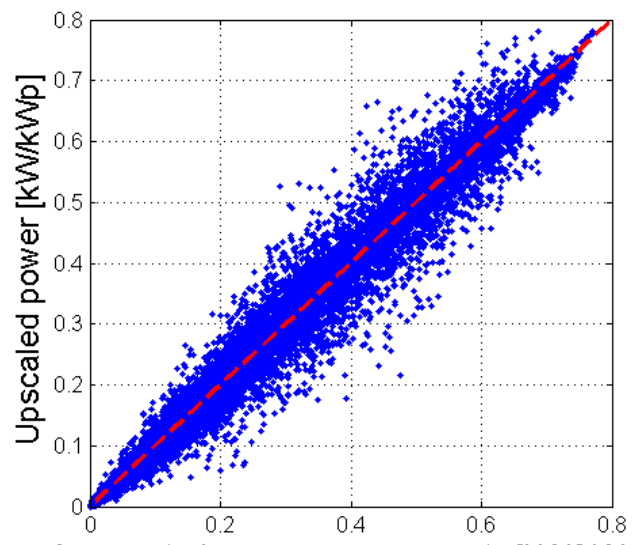

Aggregated power measurements [kW/kWp]

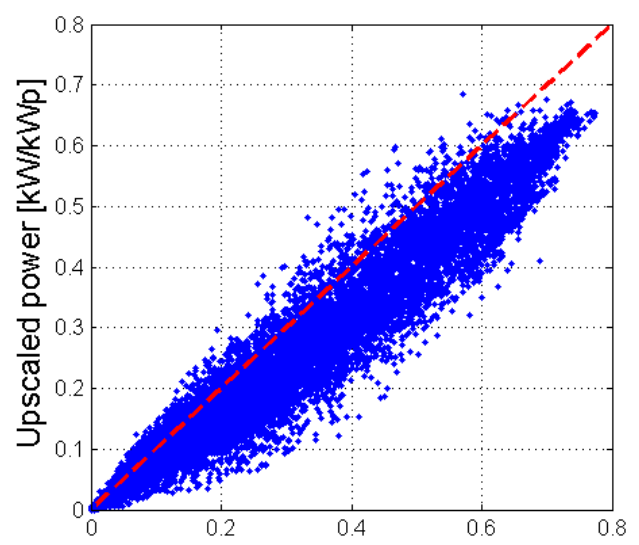

Aggregated power measurements [kW/kWp]
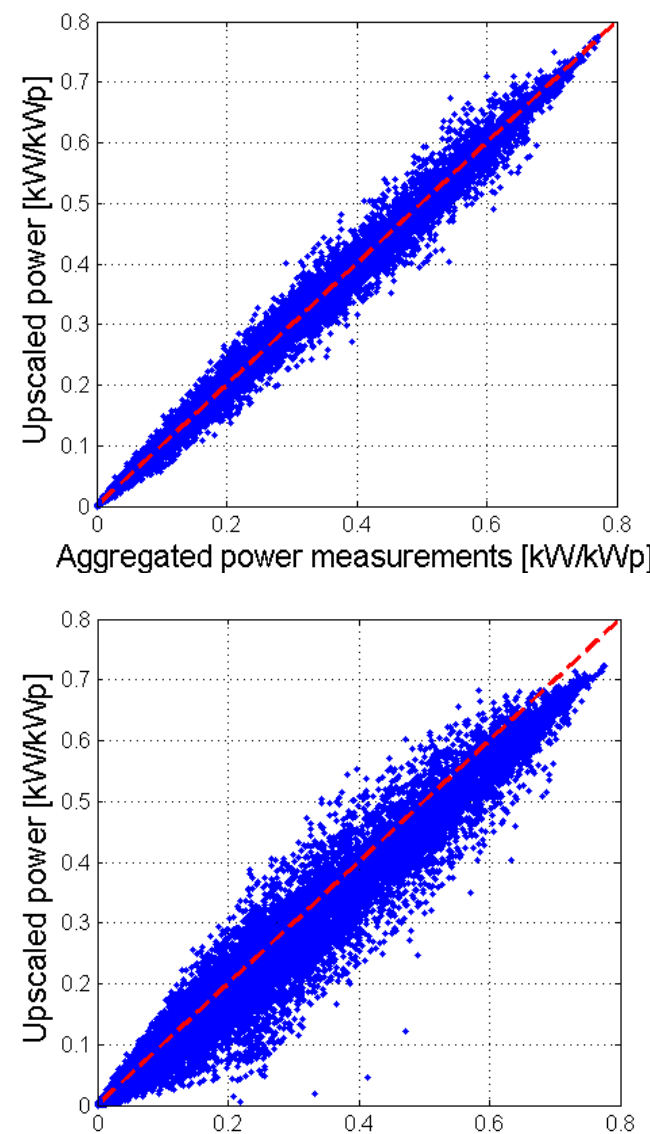

Aggregated power measurements [kW/kWp] 
(c) 30 reference plants, RMSE $=0.0131 \mathrm{~kW} / \mathrm{kWp}$

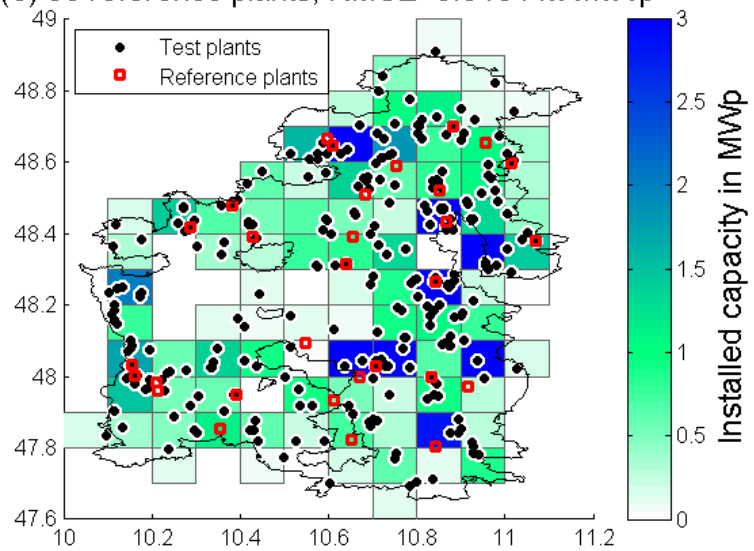

(g) 30 reference plants, RMSE $=0.0328 \mathrm{~kW} / \mathrm{kWp}$

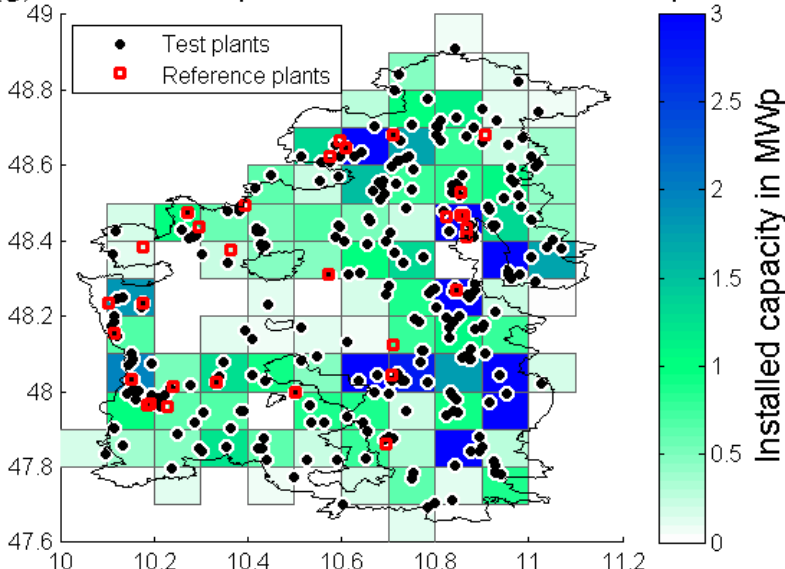

(d) 100 reference plants, RMSE $=0.0083 \mathrm{~kW} / \mathrm{kWp}$

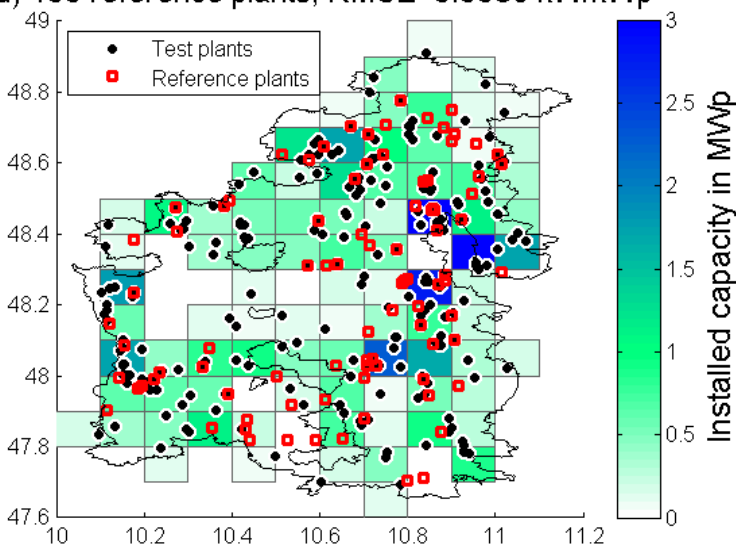

(h) 100 reference plants, RMSE $=0.0235 \mathrm{~kW} / \mathrm{kWp}$

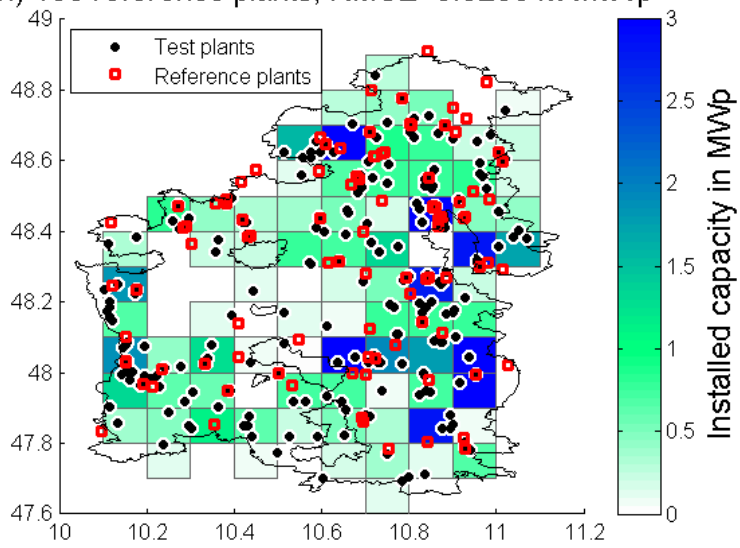

Preprint submitted to Solar Energy in January 2016

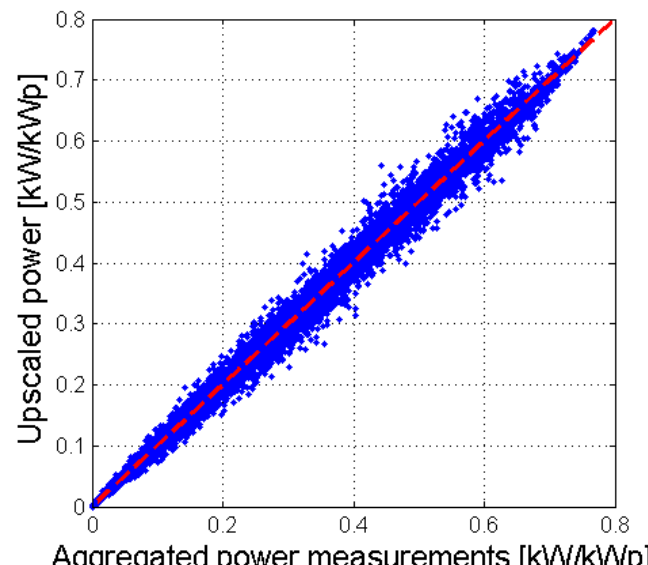

Aggregated power measurements [kW/kWp]

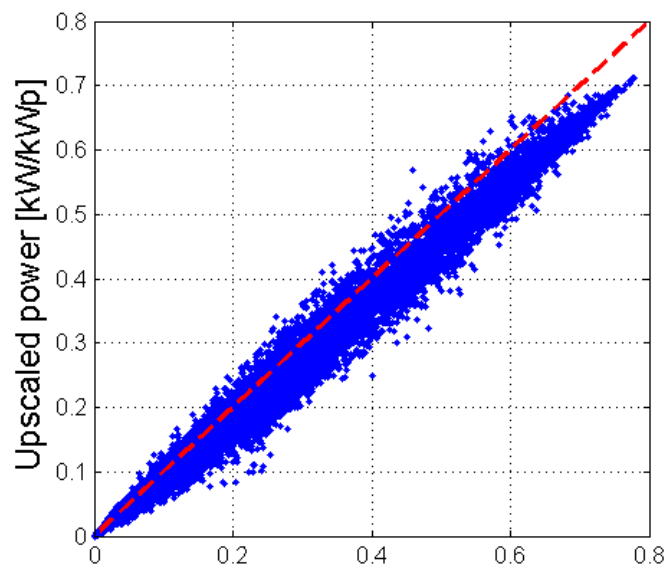

Aggregated power measurements [kW/kWp]

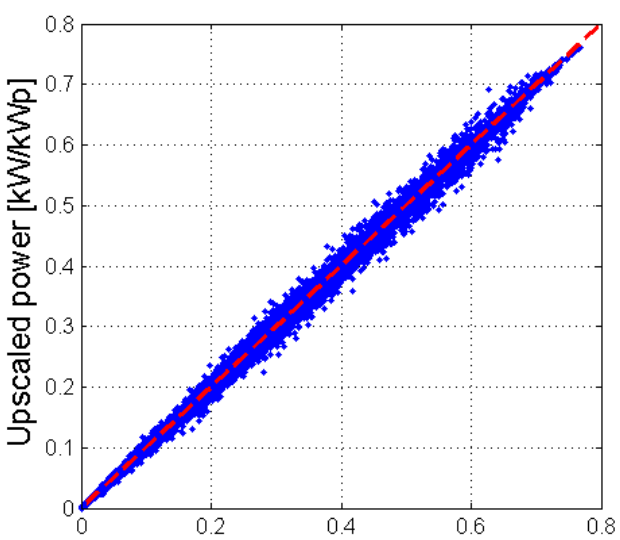

Aggregated power measurements [kW/kWp]

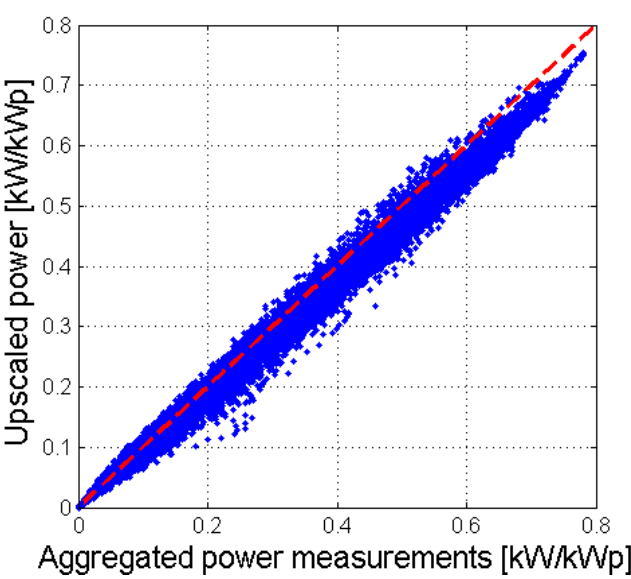

Aggregated power measurements [kW/kWp] 
Figure 11: Left maps: spatial distribution of the reference plants (red dots) and test plant (black dots). The spatially summed installed capacity of the test plants is indicated by the coloured squares. Right plots: scatter plots of the upscaling estimate as a function of the aggregated power measurements of the test plants. The runs (a)...(d) and (e)...(h) displayed at each row corresponds to the minimal and maximal RMSE values for 5, 15, 30 and 100 reference plants respectively (see Figure 9)

\section{Conclusion}

In order to understand the sources of uncertainty of the upscaling method, the two steps of this method, which are the spatial interpolation of normalized power generation and the aggregation of interpolated values have been analysed separately.

Using the available dataset of power measurements, it could be shown that the interpolation error is mainly affected by differences between the configuration parameters of the test and reference plants as well as by differences in meteorological conditions between the test and reference plants. The effect of differences in meteorological conditions increases with the distance between the un-metered and reference plants: a fast increase of the error can be observed at short distance and this increase is smaller at longer distance. Differences in configuration parameters such as module orientation are responsible for the larger errors and can result in RMSE values of up to $0.15 \mathrm{~kW} / \mathrm{kWp}$.

The RMSE has been found to decrease when individual terms are aggregated, which is well known from the literature. This decrease of the RMSE during the aggregation results from the fact that interpolated power time series at individual plant are to a certain extent independent so that the errors terms vanish during the summation and can be explained by the central limit theorem. In the considered case study, a fast reduction of the upscaling error with increasing number of plants was observed when less than 50 test plants are considered. When the number of plants is larger, a decrease of the RMSE can also be observed but it is noticeably smaller. It was also found that this gain in accuracy is stronger when all plants are assumed to have the same capacity than when the actual capacity of the test plants is considered. This could be explained by above-average weights given to large plants with high local upscaling error and belowaverage weights given to small plants with small local upscaling error. This result shows that a pragmatic way to limit the upscaling error may consist in choosing, when possible, large plants in the set of reference plants, as the total upscaling error is particularly sensitive to their error.

The sensitivity of the upscaling error to the number of reference plants was evaluated. Here again, the upscaling error exhibits a strong decrease with increasing number of reference plants when less than 20 reference plants are used. When more reference plants are used a gain of accuracy with increasing number of reference plants can still be observed but the improvement is smaller than with a smaller number of reference plants. This analysis shows that the error of the upscaling method can be rather large when the number of reference plants is too small (in our case less than 20). With the used data, no significant change occurs when more than 70 reference PV plants are used. Nevertheless, it could be observed that even when a large number of reference plants are used, the RMSE can take values between 0.010 and $0.025 \mathrm{~kW} / \mathrm{kW}_{\mathrm{p}}$ depending on the choice of the reference plants. 
It was finally shown that the average distance between the reference and test plants represents a good predictor of the upscaling error when there is a good match between the characteristics of the test and reference plants. This parameter may thus be used to choose a set of reference plant or to assess/predict the quality of a set of reference plant. However, the similarity between the characteristics of the reference and test plant has also to be considered. This aspect has not been analysed in this paper because only a limited dataset was available for the study. Analysing the representativeness of the reference plants would require analysing numerous plants including small plants that are underrepresented in our dataset. This analysis may thus represent a continuation of the present work.

The results presented in this article have been obtained with the analysis of the power measurements of a set of medium to large plants. It is now questionable to which extent these results can be applied to another set of plants with different characteristics. It is reasonable to expect that considering smaller plants would increase the variance of the plant characteristics, as those are more often mounted of roofs than large plants, which exhibits a larger spread of tilt and azimuth angles. As a result, the effect of the plant characteristics on the dispersion of the RMSE values would increase in the different analysis presented in this paper. At this exception, we can consider that the main results of this analysis can be extended another set of PV plants. A possible continuation of this analysis could however consist of an extension of the present error analysis with a larger and more representative set of PV plants. 


\section{References}

[Schierenbeck et al 2010] Schierenbeck, S., Graeber, D. Semmig A., and Weber A., 2010, Ein distanzbasiertes Hochrechnungsverfahren für die Einspeisung aus Photovoltaik, Energiewirtschaftliche Tagesfragen

[Lorenz et al 2009] Lorenz, E., Heinemann, D., Beyer H. G. und Schneider, M.: Solarleistungsvorhersage zur Netzintegration von Solarstrom. Proc. 24. Symposium Photovoltaische Solarenergie, Staffelstein, März 2009.

[Saint-Drenan et al 2011] Saint-Drenan, Y.-M., S. Bofinger, B. Ernst, K. Rohrig, T. Landgraf, Regional Nowcasting of the Solar Power Production with PV plant Measurements and Satellite Images, Proc. of ISES Solar World Congress 2011, International Solar Energy Society (ISES), Kassel, Deutschland, (09/2011)

[Thomaschki 2011] Thomaschki K., Bundesnetzagentur für Elektrizität, Gas, Telekommunikation, Post und Eisenbahnen, January 7, 2011, Positionspapier zur verbesserten Prognose und Bilanzierung von Solarstromeinspeisungen, Retrieved on March 2011 from:

www.clearingstelle-eeg.de/files/BNetzA_Positionspapier_Solarstromeinspeisung.pdf

[Hoffmann 2011] Dr. Peter Hoffmann (2011) „Systemverträglichkeit von Photovoltaik - neue Herausforderung für die ÜNB“, FGE-Kolloqium RWTH Aachen, 09.06.2011

[Shepard 1968] Shepard, Donald (1968). A two-dimensional interpolation function for irregularly-spaced data. Proceedings of the 1968 ACM National Conference. pp. 517-524.

[Remund et al. 2015] J. Remund, C. Calhau, L. Perret, and D. Marcel, "Characterization of the spatio-temporal variations and ramp rates of solar radiation and PV," International Energy Agency (IEA), IEA PVPS T14-05:2015, 2015.

[Hoff Perez 2010] T. E. Hoff and R. Perez, "Quantifying PV power Output Variability," Solar Energy, vol. 84, no. 10, pp. 1782-1793, 2010.

[Hoff Perez 2012] T. E. Hoff and R. Perez, "Modeling PV fleet output variability," Solar Energy, vol. 86, no. 8, pp. 2177-2189, 2012 